\title{
Examining the Longitudinal Associations between Repeated Narration of Recent Transgressions Within Individuals' Romantic Relationships and Character Growth in Empathy, Humility and Compassion.
}

\author{
Laura E.R. Blackie \\ University of Nottingham \\ Kate C. McLean \\ Western Washington University
}

Accepted for publication at European Journal of Personality published by SAGE. This article may not exactly replicate the final version published in the SAGE journal. The final published article can be found here:

https://doi.org/10.1177/08902070211028696

Author Note: Laura E. R. Blackie, School of Psychology, University of Nottingham, Nottingham, Nottinghamshire, NG7 2RD, UK; Kate C. McLean, Department of Psychology, Western Washington University, Bellingham, WA 98225, USA.

Acknowledgments: This publication was made possible through the support of a research grant awarded to Blackie and McLean through the Pathways to Character project (\#60699) from the John Templeton Foundation. The opinions expressed in this publication are those of the authors and do not necessarily reflect the views of the John Templeton Foundation.

We would like to sincerely thank all the people who helped with this project, including our project coordinator Katie Turner and Kody Tiemersma, Haley Wilson, Marissa Collins and Isabella Koepf whom coded the narrative data. We are very grateful to Moin Syed for his advice and guidance on data analysis. We thank James Dansey for his advice on using RStudio source code. We are grateful for the advice and support from all our colleagues on the Pathways to Character project, including Eranda Jayawickreme, Frank Infurna, Marie Forgeard, Maike Luhmann, Igor Grossmann, William Chopik, Richard Lucas, Joanne Chung, Gloria Luong, Rebecca White, Elaine Cheung, Patricia Moreno, Aaron Heller, William Fleeson, Ann Marie Ropeke, Michael Furr, Patricia Frazier, Crystal Park and Howard Tennen. Last, but by no means least, we sincerely thank all our participants who made this research study possible.

Correspondence concerning this article should be addressed to Laura E. R. Blackie, School of Psychology, University of Nottingham, University Park, Nottingham, Nottinghamshire, NG7 2RD, UK. Telephone: +44 (0115) 95 15307; Email: laura.blackie@nottingham.ac.uk 


\begin{abstract}
:
(200 words)

This prospective longitudinal study examined whether repeated written narration of relational transgressions was associated with increases in empathy, humility and compassion over one year. Although engagement in reflective and meaning-making processing styles has been theorized to facilitate adversarial growth after adversity, existing research has been limited by methodological issues and has yet to examine whether this mechanism is associated with character trait changes over time. Participants provided ratings of trait empathy, humility and compassion in 5 waves at 3-month intervals. In wave 2, participants provided a written narrative describing a recent relational transgression against their romantic partner. Participants then engaged in repeated narration of recent romantic transgressions in waves 3 through 5. The narratives were coded for redemption, positive self-event connections and degree of personal responsibility taken. Linear growth curve models were used to examine the extent to which these narrative themes were associated with character growth. Overall, there was little consistent and robust evidence across models that narration was associated with changes in empathy, humility and compassion. The implications for research into adversarial growth are discussed in reference to the appropriateness of operationalizing adversarial growth as character growth and the extent to which relational transgressions can facilitate adversarial growth.
\end{abstract}

Key words:

Adversarial Growth, Narration, Transgressions, Autobiographical Reasoning, and Romantic Relationships 


\section{Introduction:}

The notion of adversarial growth has attracted scientific attention over the past three decades. Researchers have called for work to understand recovery from adversity more broadly than simply resilience - the absence of psychopathology - to examine the full range of human experience by incorporating the possibility for the capacity for psychological growth and self-development through adversity (Linley \& Joseph, 2005). This notion of adversarial growth shares some similarities with the research on mental health recovery that has moved definitions of recovery beyond clinical symptom remission to focus on the subjective experience of the individual, and the process of changing aspects of their lives to live a meaningful and satisfying life in the context of mental illness (Slade et al., 2017).

Adversarial growth is not the outcome of a passive recovery process, nor is it considered to be a default reaction to adversity (Tedeschi \& Calhoun, 2004). Rather, researchers have proposed that adversarial growth may occur for some individuals depending on the cognitive-emotional approach used by the individual to process and make meaning from their experience of adversity. Specifically, processing styles that promote cognitive accommodation (Joseph \& Linley, 2005), in which reflection on the event leads to positive changes in the meaning and significance of the impact of the adversity are theorized to lead to adversarial growth (see also Pals, 2006). The process of cognitive accommodation (also described as deliberative rumination in this literature; Cann et al., 2011) is enhanced through the process of narration, which is itself is a reflective process of interpreting the significance of an event on one's identity, and is considered a mechanism for personality development (e.g., McLean et al., 2007). Therefore, in this article, we examined whether the act of written narration is a mechanism for facilitating adversarial growth. To be sure that we could sample individuals who would be likely to have experienced adversity, in a short-term prospective design, we examined this in one particular domain overcoming adverse and challenging experiences in individuals' romantic relationships.

Building on existing research that has examined the associations between the narration of interpersonal transgressions and character strengths (e.g., Mansfield et al., 2015; Mansfield et al., 2010; see also Pasupathi \& Wainryb, 2010), we investigate the extent to which the act and style of written narration used to describe relational transgressions is associated with increases in relational character traits of empathy, humility and compassion over time. In addition to investigating the role of narration in facilitating adversarial growth, our study addresses some of the methodological concerns that have been raised with the existing research on adversarial growth by employing a prospective longitudinal design and avoiding the use of closed survey assessments that may promote socially desirable responding and biased self-reports of adversarial growth (see Boals \& Schuler, 2018).

\section{Research on Adversarial Growth:}

The notion of adversarial growth is broadly defined as positive changes that an individual identifies in the aftermath of overcoming adversity, which represent a shift in pre-adversity functioning and a move towards optimal psychological growth 
and self-development (Linley \& Joseph, 2005). Specifically, the term adversarial growth was coined as a collective term (Linley \& Joseph, 2004) to refer to a body of research investigating this topic through different names, including post-traumatic growth (Tedeschi \& Calhoun, 1995) and stress-related growth (Park et al., 1996) among others. We further use the term adversarial growth in this article because we focus on character growth in response to everyday challenges encountered in individuals' romantic relationships, rather than after clinical trauma.

Yet, it is important to note that Tedeschi and Calhoun (2004) who coined the term post-traumatic growth intended for it to be used more broadly than the term trauma is used within clinical psychology, and they used it interchangeably in their own research with descriptions such as 'highly stressful events'. Other researchers have further questioned the assumption that experiencing clinical trauma will result in a special and unique form of adversarial growth, citing the lack of evidence for a minimum threshold of schema shattering clinical trauma necessary to facilitate such an outcome (Seery \& Kondrak, 2014). Furthermore, as outlined in the next section, the perspective taken in this article is based on the narrative identity approach to personality development, which proposes that it is not merely the occurrence of the event, or severity of the event that is significant, rather it is the way it is interpreted and narrated by the individual that is most important for promoting well-being and psychological growth (e.g., Adler et al., 2016).

Given the broad conceptualization of adversarial growth as positive changes to pre-adversity functioning, it has been operationalized and measured in several different ways. Most commonly it is measured as perceptions of changes in five life domains: relationships, personal strength, openness to opportunities, appreciation of life and spirituality (Tedeschi \& Calhoun, 1996). Others have argued that there is value to defining and measuring it through well-researched constructs that capture optimal functioning, such as eudaimonic well-being (Joseph et al., 2012). Most recently, Jayawickreme et al. (2020) have called for more rigorous investigation of adversarial growth in terms of positive personality change. Of relevance to the current study, one operationalization explored by Jayawickreme et al. (2020) was in terms of the development of character strengths over time, and more broadly, the act of narration was discussed as a possible mechanism for facilitating personality change processes (McLean et al., 2007; see also Adler et al., 2015).

The experience of adversarial growth is not a given. The extent to which an individual will experience it is dependent on how they process and make sense of their experience. Specifically, cognitive-emotional processing styles that promote self-reflection on the event with a focus on meaning making and the modification of schemas in light of one's experiences have been proposed to be key mechanisms for facilitating adversarial growth (Park, 2010; Tedeschi \& Calhoun, 2004), providing the meaning made and any adjustments to schemas are positive in nature (Joseph \& Linley, 2005). Yet, these processes are viewed as insufficient to facilitate adversarial growth on their own. Some researchers have argued that for adversarial growth to manifest into enduring and meaningful change in individuals' lives, then the insights gained through self-reflective meaning-making processes need to be incorporated into their life story (Tedeschi \& Calhoun, 2004; Pals \& McAdams, 2004). It is the revision of the life story that is theorized to help individuals integrate these insights 
into their identity through the formation of a coherent narrative that connects their past with how their recent experience has motivated them to change aspects of their personality moving forward. Although we did not examine change in the life story in this study, we took the first step in testing this hypothesis by examining whether individual differences in patterns of narration over time predicted changes at other levels of personality.

Drawing on recent theoretical advancements, we examine whether narration is a mechanism for adversarial growth in character traits over time in this study. We reasoned that if narrating adverse and challenging experiences results in enduring shifts to individuals' pre-adversity functioning, then changes should be observable as positive changes to individuals' dispositional character. We further defined and measured adversarial growth in this study as changes in dispositional empathy, humility and compassion because similar to other researchers we reasoned that the positive changes observed after adversity would depend on the nature of the event experienced (Blalock et al., 2014). As our focus was on stressful and adverse events in romantic relationships, we measured relational character traits associated with conflict resolution and the maintenance of healthy and satisfying relationships (Burnette et al., 2009; Paleari et al., 2005; Sandage \& Worthington, 2010; Worthington, 1998).

Our study design also offers significant methodological improvements to the existing research on adversarial growth. The most significant and well documented critique of this research being the prevailing use of cross-sectional and retrospective study designs and assessment tools to examine how individuals change in response to adversity over time (see Jayawickreme et al., 2020; Tennen \& Affleck, 2002). The majority of the published longitudinal studies also tend to use assessment tools that measure individuals' perceptions of how they believe they have changed - rather than current-standing change over time in relevant domains - and often do not have pre-adversity baseline data (Jayawickreme \& Blackie, 2014). Furthermore, studies that have examined the relationship between these two assessment strategies have found them to be small or uncorrelated, suggesting that retrospective assessments are unable to capture adversarial growth as it has been originally theorized (Boals et al., 2019; Frazier et al., 2009; Owenz \& Fowers, 2018; Yanez et al., 2011). This current study addresses these issues by using a prospective longitudinal design, collecting individuals' baseline standings on the traits of empathy, humility and compassion and enabling pre-to-post change in these traits to be observed over 12months after the individual has committed a transgression in their romantic relationship.

Additionally, this study avoids some of the methodological issues associated with the existing positively framed self-reported closed survey questionnaires used to assess adversarial growth. The wording of items in these questionnaires is not neutral; individuals are asked to report the extent to which they have experienced each positive change (e.g., a greater willingness to express emotions) using a Likert scale from no change to a very large degree of positive change (cf. Tedeschi \& Calhoun, 1996). Recently, Boals and Schuler (2018) demonstrated that self-reports of illusory adversarial growth were reduced when the wording of questions was made neutral and individuals were given a response scale that enabled them to 
report positive and negative change on each item. Specifically, while self-reports on the standard questionnaire were positively correlated with avoidance coping and PTSD, the revised questionnaire was negatively correlated with these outcomes and further positively correlated with quality of life. This current study further reduces the possibility for socially desirable and biased responding because individuals are reporting their experiences in their own words without the presence of any demand characteristics.

\section{Repeated Narration as a Mechanism for Adversarial Growth:}

We examine narration as a mechanism for adversarial growth because the act of narration involves a reflective process of interpreting and understanding the psychological significance of past events (Pals, 2006). The process of autobiographical reasoning (Habermas \& Bluck, 2000; Pasupathi et al., 2007) is considered fundamental to personality development and well-being, and is where an individual engages in self-reflective thought about past events and then connects the meaning from these insights to their present and future conceptions of the self. Importantly, this process is not static. Individuals will revise the connections they make between the significance of past events and their identity, as they further reflect on events, encounter new experiences and share these experiences with others (e.g., Josselson, 2004; McLean \& Pasupathi, 2012). However, there are also reliable between-person differences in this narrative style that we reasoned capture the extent to which individuals engage in the cognitive-emotional processing deemed necessary for adversarial growth (cf. Tedeschi \& Calhoun, 2004). Critically, these individual differences in narration can function to reinforce aspects of the self and thereby promote stability in narrative identity, or promote change and evolution in the life story (Adler, 2019; McLean et al., 2019; Thorne et al., 1998; Syed \& Azmitia, 2010). The latter was the focus of this current study, where we examined whether individual differences in narrative style when reconstructing past relational transgressions facilitated character growth over time.

The type of narrative constructed after adverse and challenging experiences is critical in determining whether adversarial growth is facilitated. In this study, we specifically focused on patterns of narration that are theoretically and empirically most associated with adversarial growth. The narrative theme of redemption shares conceptually the most similarity with adversarial growth because a key component of the redemptive narrative is the construction of a story that turns emotionally negative experiences into positive outcomes (McAdams, 2006). Research has found that narrating difficult and challenging experiences using redemption is associated with improved health and functioning over time. Specifically, Adler et al. (2015) observed that individuals whom narrated a difficult health experience with themes of redemption and agency showed improved mental health over a 4-year period, and Dunlop and Tracy (2013) found the use of redemptive narratives were associated with sobriety over 4-months among a sample of recovering alcoholics (when compared to individuals whom did not use redemption). Furthermore, of direct relevance to the experiences in focus in the current study, Slotter and Ward found that individuals who reflected on a recent dissolution of a romantic relationship by journaling over 4-days reported lower levels of emotional distress 
the subsequent day when they used greater redemptive imagery in their journal entries.

A second narrative theme that is conceptually linked to processes facilitating adversarial growth is self-event connections (Pasupathi et al., 2007). Self-event connections are a form of autobiographical reasoning, in which individuals meaningfully connect a past event to current understandings of themselves. Importantly, the connections can be negative or positive in nature. For example, an individual may narrate a negative self-event connection between one of their recent transgressions and their self, such that they view their hurtful actions as indicative of their worthlessness as a romantic partner. Alternatively, an individual may make a positive self-event connection between a recent transgression and their self, such that they view their hurtful actions as an opportunity to develop self-understanding that leads to personal growth and greater empathy as a partner. Thus, theoretically, it is predicted that positive self-event connections are critical to promoting adversarial growth. In a cross-sectional study where participants narrated a traumatic experience from the past, Merrill et al. (2016) found that positive selfevent connections were correlated with lower levels of distress and higher levels of adversarial growth. Furthermore, support for the role of positive self-event connections and positive functioning was found in one of the few longitudinal repeated narration studies to date. Lilgendahl and McLean (2020) found that individuals who narrated high point experiences in college with positive self-event connections reported higher levels of life satisfaction over the first year of their transition to college. Relatedly, in another longitudinal study, Lodi-Smith et al. (2009) observed that close conceptual neighbors of positive self-event connections - positive affective tone and exploratory processing - were associated with improvements in emotional health and changes in the traits of emotional stability and conscientiousness over the 4-years of college. Evidence for personality development in relation to narration can also be found in mid-life, with those who narrated life challenges with positive resolution showing increases on ego resiliency (Pals, 2006).

Finally, the narrative theme of personal responsibility is critical to facilitating adversarial growth in the context of narrating interpersonal transgressions within romantic relationships. It is the process of accepting responsibility through apology for transgressions committed against romantic partners that is argued to be integral to conflict resolution and for repairing the relationship (Schumann \& Dweck, 2014; Schumann \& Ross, 2010). However, this might be easier said than done. Researchers have found that individuals, at least in Western cultures, find ways to minimize their culpability for the harm caused by their actions. Specifically, Cameron et al. (2002) had couple dyads participate in a study where one partner was randomly assigned to write about a transgression they had enacted and caused, while the other partner wrote about the same transgression from a victim perspective. The narratives were coded and distinctions were found depending on the partner who narrated the event; the perpetrator of the harm minimized the degree of blame and the negative consequences of their actions when compared to the victim's account of the same event. Interestingly and of great relevance to this study, perpetrators also perceived greater improvements in their selves and their relationships than the victim. Yet, it 
is not always the case that individuals will seek to avoid responsibility. Schumann and Dweck (2014) found that individual differences in the extent to which people viewed personality as incremental and malleable predicted greater ability to take responsibility for their own transgressions. Thus, on the basis of this research, we predicted that the degree of personal responsibility taken in the written narrative of the transgression would be an important determinant in whether individuals show change in relational character traits over time.

\section{Current Study Design and Hypotheses:}

In this article, we report on a pre-registered prospective longitudinal study that examined whether repeated narration of recent romantic transgressions over 1-year was associated with increases in individuals' character trait levels of empathy, humility and compassion. We build on existing and nascent research on the role of narration in interpersonal transgressions that has demonstrated crosssectionally individual differences in narrative themes that promote self-reflection and meaning-making are associated with individual's self-reported levels of wisdom, self-compassion and forgiveness (Mansfield et al., 2015; Mansfield et al., 2010). Our study design not only addresses important methodological limitations from previous research (Jayawickreme et al., 2020), it also broadens the conceptual scope of research into adversarial growth in two important ways. First, we examine a key theoretical, yet under tested mechanism, and second, we broaden investigation into the types of the events that may facilitate adversarial growth from unanticipated traumatic experiences to events where the individual has to reconcile their own actions and self-reflect on the type of person they want to be moving forward (e.g., Blackie et al., 2016).

We hypothesized that individual differences in the narration of interpersonal transgressions across the study period with higher levels of redemption, positive self-event connections and personal responsibility would facilitate character growth in the relational traits of empathy, humility and compassion. We further controlled for the influence of potential covariates, including gender and narrative word count among others.

\section{Method}

Design: We designed a prospective longitudinal repeated narration study to examine whether the type of narrative constructed after a relational transgression was associated with character growth in empathy, humility and compassion over a year. There were 5 waves of data that were collected at 3-month intervals across 1 year. The main outcome variables were trait empathy, humility and compassion and were collected in all 5 waves. In wave 2, participants provided a written narrative in which they described a specific occasion where they were responsible for hurting or upsetting their romantic partner between wave 1 and 2 . The romantic transgression was the prospective experience that was the focus in this study. Participants were asked to write about these recent romantic transgressions in waves 3 through 5. 
Participants: The data analyzed in this paper is from 311 participants (after exclusions based on a priori criteria as outlined in the results section). There were 195 females, 112 males, 3 participants who are non-binary or transgender and 1 participant who did not provide their gender. 179 participants (58\%) were from the UK and 132 participants (42\%) were from the USA. The mean age (SD) reported at wave 1 was 26.12 (7.26) and ranged from 18 to 60 years. Individuals in the UK sample identified as White British (71\%), White European (10\%), Chinese (5\%), Indian (2\%), Black African (2\%), Black Caribbean (2\%), Pakistani (2\%), or selected other or preferred not to provide this information (6\%). When asked about their sexual orientation individuals in the UK sample identified as straight (82\%), bisexual $(11 \%)$, gay $(5 \%)$ or selected other or preferred not to provide this information (2\%). Individuals the US sample identified as White or Caucasian (73\%), Black or African American (6\%), Asian, Asian American, or Pacific Islander (6\%), Latino or Hispanic (6\%), White European (4\%), Indian (1\%) or selected other or preferred not to provide this information (4\%). When asked about their sexual orientation individuals in the US sample identified as straight or heterosexual $(77 \%)$, bisexual (11\%), mostly straight or heterosexual (7\%) or gay or lesbian (5\%).

We had planned to recruit 600 participants (300 from UK and USA) in line with recommended sample size guidelines for SEM and growth models (Kline, 2010). Our inclusion criteria were adults aged 18 years or older who lived in the UK or USA and had been in a romantic relationship with their current partner between 6 months and 2 years at the point of recruitment. Although there is no consensus on the thresholds for when people form strong and secure romantic attachments to their partner (Fraley, 2019), we decided a priori to recruit participants in fairly new to short-term relationships. We selected the 6-months to 2-year timeframe because we reasoned that transgressions might be less likely (or noticed and reported less) in long-term relationships, yet we wanted to recruit participants whom were likely to be in committed relationships for the full study duration. In total 843 participants expressed an interest and met the study inclusion criteria. Of the 843 participants invited to wave 1, 400 participants (47\%) completed wave 1 . We used this total to calculate the response and attrition rates (see Table 1). Three participants withdrew from the study after wave 1 and 22 participants withdrew after wave 2 . This left a sample of 397 participants that were invited to participate in wave 2 and a sample of 375 participants through waves 3 to 5 .

\section{Table 1:}

Participant response rates and attrition across 5-waves

\begin{tabular}{lccccc}
\hline & Wave 1 & Wave 2 & Wave 3 & Wave 4 & Wave 5 \\
\hline Total invitations: & 843 & 397 & 375 & 375 & 375 \\
Total responses: & 400 & 346 & 311 & 273 & 264 \\
Completion rate (\%): & $47.4 \%$ & $86.5 \%$ & $77.8 \%$ & $68.3 \%$ & $66.0 \%$ \\
\hline Attrition rate (\%): & -- & $13.5 \%$ & $22.2 \%$ & $31.7 \%$ & $34.0 \%$ \\
\hline
\end{tabular}


Participant recruitment strategies: Participants were recruited between May 2018 and September 2018. We posted online study advertisements on social media (e.g., Twitter, Facebook, Reddit, Gumtree and Craigslist) and posters in public venues (e.g., university campuses, libraries, entertainment venues and cafes in the local areas of the authors' universities). We also used a participant recruitment website (https://www.callforparticpants.com) and we paid for recruitment services from Qualtrics using their Research Services Market Research Panel, where we specifically tried to recruit equal representation of genders. Participants were told that we were interested in their personality growth in romantic relationships and in addition to filling out questionnaires about their personality and relationship quality, they would be asked to provide written descriptions of high points and low points recently experienced in their relationships. For participants whom expressed an interest in the study, we did a pre-screen process to ensure their suitability and to give them some further information on the narrative tasks, which would involve writing about some potentially difficult times in their current relationship. For the participants in the UK, the research coordinator did the pre-screen on the phone, but participants in the US answered parallel questions and acknowledged study task information via an online survey.

Participant compensation: Participants were compensated with a $£ 10$ ( $\$ 10$ in the US sample) Amazon voucher for each survey they completed. Additionally, for each wave, all participants who had completed the survey were entered into a prize draw with the chance of winning 1 of 4 possible $£ 50$ (\$50) Amazon vouchers.

Study procedure: The ethics committee of each author's university granted ethical approval for the study procedures. Data was collected between May 2018 and November 2019. Participants completed up to 5 surveys in total with each survey administered 3-months after the last one. Participants were given a 2-week period to return survey responses for each wave. It was possible for participants to save their responses and return to finish the survey within the set timeframe that the survey was open for. All the surveys were programmed and administered using Qualtrics software and each survey took an estimated completion time of between 45-60 minutes. At the start of each survey, participants read an information sheet and provided informed consent. At wave 1, all 843 participants (see table 1) whom had expressed an interest in the study were invited to participate. In the following waves (waves 2 to 5), we invited the 400 participants whom had responded to wave 1 to each subsequent wave with the exception of the 25 participants who withdrew from the study.

In all waves, participants answered questionnaires about their character (i.e., empathy, humility and compassion), personality traits, and indicators of the quality of their romantic relationship (i.e., satisfaction). In waves 2 to 5, participants were asked to provide a written narrative describing a recent relational transgression where they had hurt or upset their romantic partner. They were also asked to write a narrative about recent relational transgressions in waves 3 through 5 . The narratives on the relational transgressions were the focus of this study. To mask our focus on the relational transgressions and to alleviate the potential for upset in 
reflecting solely on these negative events, we also asked all participants to write a narrative about a recent high point in their romantic relationship. These positive events were not the focus of this analysis and will not be described in this article. In the next section, we outline only the questionnaires and narrative instructions that were used to analyze the research questions for our pre-registered hypotheses for this article. However, we have uploaded our study codebook to the Open Science Framework (OSF) to enable researchers to see all the variables that we examined in this study along with information on which wave the variables were administered in.

Materials: The study materials, data and analysis scripts used for this article can be found here: https://osf.io/y2zds/?view_only=07d22ef4ab504fdebbd15e5ef0191d6f

Transgression narrative prompts: We asked participants to write a narrative about a recent transgression that they had committed against their partner at wave 2 through 5 . In wave 2, we instructed participants to write a narrative about "an incident that had occurred since the last survey (i.e., wave 1) where "you either said or did something to upset or hurt your [romantic] partner's feelings. You can also report something you did that your partner is unaware of, but you feel doesn't reflect the type of person you want to be in your romantic relationship." We told participants that "the type of incident you report is up to you, but we ask that you report something that you felt was significant in some way since the last survey." Participants were given a free text box, and asked to describe in full sentences: what happened, when it happened, who was there, what they were thinking and feeling at the time and why this experience was meaningful to them and their relationship.

To help participants identify potential incidents we asked them to complete an adapted version of the transgression occurrence measure (McCullough et al., 2003) before writing about their transgression. The original measure asked about the frequency of interpersonal transgressions individuals had experienced in their relationships in the past 14 days, including acts of omission (e.g., feeling underappreciated) and commission (e.g., aggressive behaviors) that range in severity. The individual reported the frequency of each transgression using a Likert scale from ' 0 ' (not at all) to '6' (constantly). We adapted this questionnaire to ask about the extent to which they had enacted these transgressions against their romantic partner in the past 14 days (e.g., "I failed to appreciate my partner adequately"). To reduce the risk of socially desirable responding we adapted the questionnaire instructions to read: "Sometimes we do not act in line with our best selves, even in our relationships with those we care about the most. A certain degree of conflict in romantic relationships is common. We would like you to indicate how frequently you have acted either consciously or unconsciously in the manner outlined in the items below in the last 2-weeks." Participants responded on the same 7-point scale as in the original questionnaire. The data from this scale was not analyzed (nor did we $a$ priori plan to analyze it in our pre-registration). It was included simply to help participants reflect on transgressions prior to writing their narrative. 
In wave 3 through 5, we asked participants to write about the transgression they had identified and narrated in wave 2. Specifically, we instructed participants: "In the last survey, you were asked to describe an incident when you either said or did something to upset or hurt your partner's feelings. Please write about this incident again. Don't worry about writing it in exactly the same way, as we are just interested in how you think about it now." Participants were then asked to write in full sentences and given the same prompts as outlined in the previous paragraph. After participants had written the narrative, we asked them if the incident provided was the same as the one in the previous survey (yes/no/unsure) and we used this as a covariate in our analysis. We also told participants in the instructions that if they did not remember the incident they reported in the last survey that they could write about another transgression that happened in the last 3-months (since the previous survey). For participants who provided transgression narratives, 30\% reported that the transgression reported at wave 3 was the same as from the previous wave, 37\% reported the same transgression in wave 4 , and $36 \%$ in wave 5 . Thus, in most cases, participants were reporting different transgressions across the study period that had occurred with the timeframe since the last survey (i.e., last 3-months).

\section{Narrative coding of Transgressions:}

We coded the narratives for redemption, positive self-event connections and personal responsibility as per established guidelines (see Syed \& Nelson, 2015).

Redemption. All narratives were coded into one of four mutually exclusive valence categories: redemption, contamination, stable negative or stable positive (e.g., McAdams et al., 2001). Redemption was defined as a self-evidently negative event leading to a positive outcome. Contamination was present if a good or positive event or state became bad or negative. If there was no change in the valence of the narrative, then it was either rated as "stable negative" or "stable positive". Four undergraduate coders were trained on the system, and then completed a reliability phase with an expert rater (second author). The training and reliability coding was done across various types of prompts (low points, high points, and transgressions), and 122 narratives were used for the reliability phase. All coders achieved acceptable reliability overall (kappas range from .80 - .91), and for each category: redemption (kappas range from .78 - .89), contamination (kappas range from .68 .89), stable negative (kappas range from .72 - .90), stable positive (kappas range from .61 - .83). There were quite low base rates for stable positive, so it is appropriate to report percent agreement (Syed \& Nelson, 2015), which ranged across RAs from 85\% - 95\%. After achieving reliability, coders were assigned to teams of two. Thus, each narrative was coded by two coders; disagreements were reconciled between the two coders or, rarely, with consultation from the second author.

Enhanced Redemption. Once the above coding was complete, narratives coded as redemptive were selected to code for enhanced redemption (McAdams et al. 2001). There was a potential for two "bonus points" on redemption if 
participants elaborated redemption in three different ways ${ }^{1}$, each earning one extra possible point: elaboration on redemption in the area of agency or communion (see McAdams et al., 2001 for a discussion of these three themes in relation to Tedeschi and Calhoun's (1995) conceptualization of posttraumatic growth). Enhanced agency was defined as the narration of explicit strength, confidence, or self-understanding that was directly linked to the shift towards redemption. Enhanced communion was defined as the narration of explicit reports of increased intimacy, love, caring, etc. that was directly linked to the shift to redemption. Two coders who had coded with the original redemption system trained on this system with 30 narratives, and reliability was completed with 59 cases. Reliability was acceptable (overall kappa = .80; Agency = .85; Communion $=79$ ). After achieving reliability, the two coders each coded all narratives. Thus, each narrative was coded by two coders; disagreements were reconciled between the two coders or, rarely, with consultation from the second author. These redemption scores were the ones used in the subsequent analyses.

Self-event Connections. All narratives were coded for the frequency of selfevent connections. Self-event connections are defined as any point in a narrative when the narrator explicitly links an aspect of the event to a broader understanding of their self-concept (e.g. experiencing this showed me how strong I am; Pasupathi et al., 2007). We also adapted this coding system to capture relationship-event connections. These are distinguished from self-event connections because they focus on how one behaves in or orients towards relationships. The relationship may be specific (e.g., "I have learned that I need to be more empathic with my partner.") or about relationships in general (e.g., "I have learned that I need to be more empathic in my relationships"). Both types of connection were coded according to whether an event changed or revealed a stable and pre-existing aspect of the self(e.g. "I became more independent" versus "This event showed me how independent I am"). Each connection was classified according to the valence: positive, negative, or neutral/ambiguous. In the current study, the focus for the data analysis was on positive change self-event connections. Four undergraduate coders were trained on the system, and then completed a reliability phase with 57 narratives, in which they needed to achieve reliability with an expert rater (second author). Reliability was acceptable. The overall kappas across all connections (stable/change, valence, self/relationship) ranged from .74 - .78. Kappas for distinguishing self versus relationship connections ranged from .70 - .85. Kappas for valence (positive, negative, or neutral) ranged from .76-.81. Kappas for distinguishing change versus stable ranged from .72 - .84.

Personal Responsibility. Each transgression narrative from wave 2 through 5 was coded for the degree of personal responsibility taken by the narrators for their role in the transgression. The coding scheme was this construct was developed by the research team using Weiner's (2007) definition of responsibility, whereby full

1 This system also includes a bonus point for "ultimate concerns," which focuses on growth in spiritual areas. However, this was not found in this data set. 
moral accountability is viewed as intentionally taking internal control for one's actions and an absence of mitigating circumstances. All the narratives were scored on a 4-point scale from '0' ("No responsibility") to '3' ("Full responsibility"). Two coders (second author and one other coder) independently rated 59 narratives. Intraclass correlation coefficient (ICC) estimates and their 95\% confidence intervals (CIs) were computed (ICC $=.88,95 \% \mathrm{CI}$ : .81 to .93 ). After achieving reliability, the independent coder rated the remaining transgression narratives, consulting the second author on scoring for problematic narratives.

\section{Self-report questionnaires:}

The Event Characteristics Questionnaire: We measured the perceived severity of each narrated transgression from wave 2 to wave 5 using a shortened version of the impact sub-scale of the event characteristics questionnaire (ECQ; Luhmann et al., 2020). The standard ECQ is a 38-item questionnaire where individuals report on 9 event characteristics that may differ across major life events, including the extent to which the event was challenging, caused by external factors, an extraordinary (or rare) occurrence, predictable, caused a change in worldviews or social status and asks participants to rate the emotional significance, valence of the event and the psychological impact of the event. Participants rate each item on a 5-point Likert scale from ' 1 ' (Does not apply at all) to '5' (Applies completely). We used a shortened 20 -item version of the ECQ following advice we received from the creator and firstauthor of the questionnaire (Luhmann et al., 2020) because we needed to keep our survey questionnaires short and targeted in this survey. We measured the impact of the event (e.g., severity) using these 2-items: "The event had a strong impact on my life" and "The event had long-term consequences". In the analyses reported below, we use event severity recorded at wave 2 .

Empathy: We measured trait empathy at all waves with the perspectivetaking dimension of the Multidimensional Empathy Scale (MES-PT; Davis, 1980). The MES-PT is a 7-item self-report scale, which measures how much individuals typically consider other people's perspectives when they experience interpersonal difficulties (e.g. "Before criticizing somebody, I try to imagine how I would feel if I were in their place"). Items were rated on a five-point Likert-type scale, from ' 1 ' (Does not describe me well) to '4' (Describes me very well). Past research has found this scale has good internal consistency for males $(\mathrm{a}=.71)$ and females $(\mathrm{a}=.75)$, but low two-month test-retest reliability $(.61<\mathrm{rs}>.62$; Davis, 1980$)$. The Pathways to Character project through which this study was funded specified that all studies measure empathy with this questionnaire.

Humility: We measured trait humility at all waves with the 15-item Humility Inventory (Brown et al., 2013). The humility inventory is structured around 3 dimensions: (1) esteem for others (e.g., "I try to make others feel important"); (2) systemic perspective (e.g. "I recognize I need help from other people") and (3) acceptance of fallibility ("I appreciate learning of my weaknesses"). Participants were asked to rate how much the statements described them, from ' 1 ' (strongly disagree) to ' 5 ' (strongly agree). The different dimensions can be examined separately, or a total created across all dimensions. We used the latter strategy. Past 
research has found his questionnaire to have good to excellent internal consistency $(.66<$ as $>.83)$, and three-month test-retest reliability is low to good $(.65<\mathrm{rs}>.80$; McElroy, 2017). It was specified that projects in The Pathways to Character project use this questionnaire.

Compassion: We measured trait compassion at all waves with the 5-item compassion dimension of the Dispositional Positive Emotions Scales (DPES-CS; Shiota et al., 2006). The DPES-CS measures general feelings of concern and nurturance towards others (e.g. "Taking care of others gives me a warm feeling inside"). Items are rated on a 7-point Likert scale from '1' (Strongly disagree) to '7' (Strongly agree). The scale has excellent internal consistency reliability (.80; Shiota et al., 2006), but no information was published on test-retest reliability.

Demographic information: In wave 1 , we collected information from participants on their age, gender, ethnicity and sexual orientation, as reported in the participant section.

\section{Data Analysis Plan:}

All the analyses and hypotheses examined in this paper were pre-registered on OSF. Furthermore the data and data scripts for analyses are available from this OSF private view-only link:

https://osf.io/y2zds/?view_only=07d22ef4ab504fdebbd15e5ef0191d6f

We used linear growth curve modeling to examine if how a person narrated a recently committed transgression was associated with changes in empathy, humility and compassion over the course of a year. Prior to undertaking the growth models, we first examined whether the outcome variables were sufficiently distinct to merit undertaking separate analyses for each outcome. We undertook confirmatory factor analysis (CFA) to examine the fit of three competing models - one factor, two factors and three factors. Our study sample size was not sufficient to test for longitudinal measurement invariance, therefore we a priori (as specified in our preregistration) tested for configural invariance across wave and sample location. We tested for configural invariance within each wave separately for the full sample $(\mathrm{n}=311$; reported in the results) and for the UK and US samples separately (reported in the supplementary materials). We evaluated the fit of each model across both wave and sample location using the following fit statistics: the chi-square test of goodness of fit, comparative fit index (CFI), root mean square error of approximation (RMSEA), standardized root mean square residual (SRMR), and sample size adjusted Bayesian Information Criterion (ssBIC).

We examined our linear growth models with Mplus 8.0 software (Muthen \& Muthen, 1998-2020) using full information maximum likelihood modeling with robust standard errors (MLR). We scaled time for all outcome variables (empathy, humility and compassion) at 0 for Wave 1, 3 for Wave 2, 6 for Wave 3, 9 for Wave 4 and 12 for Wave 5 to indicate the duration in months in between assessments. Our first linear growth model for each outcome did not include any narrative predictors or covariates. These models were conducted to examine general patterns of change (individual and mean-level) in the outcomes over time and determine if there was significant variability to merit the modeling of predictors and covariates. Our next set of growth models included our narrative predictors to examine within-person 
and between-person associations on the outcome variables. We next modeled the lagged associations between our narrative predictors, covariates and outcomes to determine if narration predicted changes in empathy, humility and compassion (i.e., our hypothesized direction), or if empathy, humility and compassion predicted changes in patterns of narration. Finally, we conducted linear growth models to examine between-person moderations of the perceived severity of the transgression (measured at wave 2) and all our narrative predictors.

We ran two different models with covariates for all analyses. The first model included our targeted covariates that we reasoned would be meaningfully related to the study outcomes (i.e., gender, sample location [UK/US] and whether participants narrated the same transgression in subsequent waves; i.e., repeated narration). Our second model included two additional covariates that are frequently requested by reviewers (i.e., age and word count). We report analyses only with our targeted covariates in the results section, but results with the full covariate model are included in the supplementary materials.

\section{Data Preparation:}

\section{Results}

Data exclusions: We excluded participants before conducting any of the models if they did not provide a transgression narrative at wave two. There were 39 participants who reported that they had not committed a transgression against their romantic partner between waves 1 and 2. There were a further 50 participants who left the transgression narrative blank, despite completing other questionnaires in the wave two survey. These participants were also excluded, leaving a sample of 311 participants.

Creation of narrative predictor variables: We examined the relationship between the use of redemption and positive self-event connections when reporting a transgression narrative. We reasoned that redemption and positive self-event connections might overlap sufficiently to be considered a composite variable of positive autobiographical reasoning (see McLean et al., 2020). We first created a sum score for positive self-event connections for each wave. The frequency of positive self-event connections ranged from 0 to 3 in waves 2 to 4 and from 0 to 2 in wave 5 , but most participants reported less than 2 in each wave (i.e., 95.8\%, 93.6\%, $96.9 \%$ and $97.6 \%$ through waves two to five, respectively). We then created a total for both positive self-event connections and redemption by summing across waves 2 to 5 . The correlation between the summed total of redemption and the summed total of positive self-event connections was $r(309)=0.594 p<.001$. The correlation was greater than .50 therefore we followed our preregistration and created a composite score called 'positive autobiographical reasoning' (PAR) for each wave by summing the two variables together. Our linear growth models examine the associations between positive autobiographical reasoning and empathy, humility and compassion, rather than examining redemption and positive self-event connections separately.

Analysis of Missing data: To address issues of attrition we conducted several analyses. First, we compared mean-level differences on our dependent 
variables for participants who completed only Wave $1(n=41)$ to those who completed at least one wave after Wave 1 . There were no significant differences at $p$ $<.05$ on empathy, humility, or compassion at Wave 1.

Next, we examined differences between those who completed only Wave 1 and Wave $2(\mathrm{n}=17)$ and those who completed at least one Wave after Wave $2(\mathrm{n}=$ 294) for our dependent variables (empathy, humility, and compassion) at Wave 2 , as well as narrative variables at Wave 2 (redemption, positive stable connections, positive change connections, positive stable relationship connections, positive change relationship connections, narrative responsibility, and event severity). Of these 10 t-tests, only one was significant at the $\mathrm{p}<.05$ levels Participants who completed more waves of data had higher scores on positive stable connections $(M$ $=.04, S D=.00)$ than those who completed only Wave 1 and Wave $2(M=.00, S D=$ $.25), t(292)=-3.02, p=.003, d=0.2$. Given the very low number of significant tests, and the magnitude of the difference, we do not consider this differences meaningful for future analyses.

\section{Model Testing for Outcome Variables:}

We examined 3 competing models using CFA to assess whether empathy, humility and compassion were sufficiently distinct psychological constructs to necessitate separate analyses for each outcome. In Model A, we tested the model fit of a one-factor solution in which all items from the empathy, humility and compassion questionnaires loaded onto one factor, which we called interpersonal virtues. In Model B, we tested the model fit of a two-factor solution in which all the items from the humility questionnaire loaded onto one factor and the items from empathy and compassion questionnaire loaded onto a second factor. The rationale behind this model was that behaving empathically requires both cognitive perspective taking abilities (measured with the empathy items) and feelings of care and concern for others (measured with the compassion items). In Model C, we tested the model fit of a three-factor solution in which items from the empathy, humility and compassion questionnaires were theorized to be distinct constructs and set to load on separate factors.

We ran these CFA models for wave 1 to 5 separately for the full sample. We report the results for the UK and US samples in supplementary materials, but we found the same general pattern as in the full sample. As can be seen in Table 2, the model fit was comparatively stronger for model $\mathrm{C}$ across all waves. Although the chisquare was significant for all models, it was smaller in model C for all waves. The CFI did not reach conventional standards of a good fit ( $>.90)$ in any of the competing models ${ }^{2}$, but it was stronger for model $\mathrm{C}$ in all waves. The RMSEA indicated a good fit $(<.08)$ for model C across all waves. Similarly, the SRMR was higher than the recommended conventional standard $(<.06)$, but it was lowest in model $\mathrm{C}$ and the ssBIC was lowest in model C for all waves. Based on these findings, we concluded

\footnotetext{
${ }^{2}$ However, our RMSEA for the baseline (or null model) of the CFA was lower (or equal) than 0.158 for all waves (i.e., w1 $=0.1355$, w2 $=0.1485$, w3 $=0.1488$, w $4=0.1577 \& w 5=0.1536$ ). It has been observed that if this is the case, incremental measures of fit such as the CFI may not be as informative. The source is: http://davidakenny.net/cm/fit.htm
} 
that empathy, humility and compassion were distinct psychological constructs and therefore we conducted growth curve models for each outcome separately.

\section{Linear Growth Curve Models for Empathy, Humility and Compassion:}

Examining mean-level change and variability over time: As a first step, we examined whether there was significant mean-level change and variability in each outcome over time. Starting with empathy, the variance for the intercept was 0.184 , $p<.001$, demonstrating that there was a significant amount of variability at wave 1 . For the slope, the mean was $0.005, p=.061$ and the variance was $0.001, p<.001$, demonstrating that although there was no mean-level change in empathy over time, there was significant variability in change over time. For humility, the variance for the intercept was $0.173, p<.001$ indicating that there was a significant amount of variability at wave 1 . For the slope, the mean was $0.003, p=0.275$ and the variance was $0.001, p=0.015$ demonstrating that although there was no mean-level change in humility over time, there was significant variability in change over time. These results provided empirical justification to examine our main hypotheses of whether individual differences in positive autobiographical reasoning were associated with individual differences in changes in empathy and humility over time.

For compassion however, the variance for the intercept was $0.617, p<.001$ indicating that there was a significant amount of variability at wave 1 . For the slope, the mean was $-0.005, p=0.150$ and the variance was $0.001, p=0.331$, indicating that there was neither mean-level change nor variability in change over time. There was significant within-person variability in compassion for all waves (i.e., w1: 0.290, $p<.001$; w2: 0.284, $p<.001$; w3: 0.210, $p<.001$; w4: 0.254, $p<.001$; w5: 0.234, $p<$ .001 ), and as such we only included the within-person predictors in the subsequent growth models for compassion.

Examining associations with positive autobiographical reasoning and empathy, humility and compassion over time: We report our examination of associations between positive autobiographical reasoning on empathy, humility or compassion across waves 1 to 5 including the covariates of gender, sample location, and repeated narration (Yes/No) of the transgression. To enable our analysis to run, we transformed gender into a binary variable and restricted our sample to male and female. This resulted in the exclusion of 3 participants who identified as non-binary. However, as gender was not a significant predictor of either the intercept or slope for any of the outcomes, we decided to omit gender as a covariate in subsequent analyses to permit greater inclusivity in our data set. Tables 3 to 5 report the model coefficients (standardized and unstandardized) for the outcomes of empathy, humility and compassion, respectively.

When examining empathy (see table 3), the only significant findings were on the intercept for sample location $(b=0.156)$ and positive autobiographical reasoning $(b=0.115)$. These results indicate that participants in the US reported higher baseline levels of empathy compared to participants in the UK, and those who engaged in greater positive autobiographical reasoning started out higher in 
baseline levels of empathy. There were no significant findings on the slope for empathy.

When examining humility (table 4), the only significant findings were on the intercept for sample location $(b=0.115)$ and on positive autobiographical reasoning at wave 2 and humility at wave $2(b=0.029)$. Participants in the US reported higher baseline levels of humility compared to participants in the UK, and participants who engaged in greater positive autobiographical reasoning in their transgression narrative at wave 2 reported higher levels of empathy at wave 2 . There were no significant findings on the slope for humility.

When examining compassion (table 5), only the within-person associations were modeled as our prior analyses indicated that there was no significant meanlevel change or between-person variability to predict in compassion. There was a significant association between positive autobiographical reasoning and compassion at wave $2(b=0.069)$, such that participants who engaged in greater positive autobiographical reasoning in their transgression narrative at wave 2 reported higher levels of compassion at wave 2 . There were no other significant findings.

Examining lagged model associations: We modeled the lagged associations between our predictors, covariates and outcome variables to determine if positive autobiographical reasoning predicted changes in empathy, humility and compassion (i.e., our hypothesized direction), or if empathy, humility and compassion predicted changes in positive autobiographical reasoning. We scaled time in these lagged models as outlined previously (i.e., $0,3,6,9,12$ ). However, the growth models in which empathy, humility and compassion predicted changes in positive autobiographical reasoning used data from waves 2 to 5 as narrative data was first collected at wave 2. In these models, we kept time scaled at 3 for Wave 2, 6 for Wave 3, 9 for Wave 4 and 12 for Wave 5.

We first modeled our hypothesized associations (see table 6). For empathy, the only significant associations were on the intercept for sample location $(\mathrm{b}=$ $0.147)$ and positive autobiographical reasoning $(b=0.111)$. These results were the same as reported earlier (e.g., US participants reported higher baseline levels of empathy and greater positive autobiographical reasoning was associated with higher baseline empathy). None of the coefficients were significant in the growth model for humility. For compassion, which as previously outlined only modeled the within-person associations; the only significant coefficient was the association between positive autobiographical reasoning at wave 3 and compassion at wave 4 $(b=-0.082)$. Contrary to the hypothesized direction, participants who engaged in greater positive autobiographical reasoning in wave 3 reported lower levels of compassion in wave 4.

Next, we examined whether empathy, humility, or compassion predicted changes in positive autobiographical reasoning across waves 2 to 5 (see table 7). When empathy was modeled as a predictor, the only significant association was on the intercept for empathy $(b=0.386)$. These results indicate that participants higher in trait empathy started out higher in positive autobiographical reasoning in their first transgression narrative (at wave 2). There were no significant findings for the 
slope and no other significant associations. When humility was modeled as a predictor, the only significant association was between humility at wave 2 and positive autobiographical reasoning at wave $3(b=0.136)$. These results indicate that participants higher in humility at wave 2 engaged in greater autobiographical reasoning at wave 3 . There were no significant findings for the slope and no other significant associations. None of the coefficients were significant in the growth model when compassion was modeled.

Examining interactions between event severity, narrative responsibility and positive autobiographical reasoning on empathy and humility over time: We examined the between-person interactions between event severity, narrative responsibility and positive autobiographical reasoning in predicting changes in empathy and humility over time. We did not conduct these moderation analyses for compassion, because our prior analyses indicated that there was no significant between-person variability in this outcome. For empathy, there were associations between sample location $(b=0.168)$, positive autobiographical reasoning $(b=$ 0.134 ) and event severity ( $b=0.072$ ) on the intercept (see table 8 ). The results indicated that participants from the US, who engaged in greater autobiographical reasoning and rated the transgression as more severe at wave 2 had higher baseline levels of empathy. The association between event severity and empathy was also significant on the slope ( $b=-0.007$ ), indicating that contrary to predictions, those who rated the transgression as less severe increased in empathy over time. There were also some significant interactions; there was a two-way interaction between narrative responsibility and positive autobiographical reasoning $(b=-0.095)$ on the intercept, and the slope for empathy ( $b=0.009)$.

We plotted and probed the interactions using the Johnson-Neyman technique using the LOOP Mplus function via RStudio. For the interaction on the slope (see Figure 1), we observed that the confidence intervals around the adjusted effect of autobiographical reasoning on empathy did not cross zero at 1SD above and 1SD below the moderator of narrative responsibility. These results indicated that for individuals who took higher levels of responsibility for their actions, the more autobiographical reasoning was associated with empathy over time. However, for those who took lower levels of responsibility for their actions, the less autobiographical reasoning was associated with empathy over time. Although this interaction was pre-specified and is conceptually consistent with theory, we caution against putting too much weight on this finding given that it is one of the few significant effects out of the large number of models we ran. We have included the figure for the interaction plot on the intercept in supplementary materials - the interaction was not hypothesized and the region of significance was small (i.e., between 0 and $.75 \mathrm{SD}$ above the moderator), and it was not interpretable from a conceptual standpoint.

For humility, there were no significant main effects or moderations involving event severity, narrative responsibility or positive autobiographical reasoning (see table 9). The only significant association was between positive autobiographical reasoning and humility at wave $2(\mathrm{~b}=0.032)$, indicating that participants engaging 
in greater positive autobiographical reasoning reported higher level of trait humility at wave 2 . There were no other significant associations.

\section{General Discussion}

In the present study, we examined the potential of narrative as a mechanism for adversarial growth. We examined both the degree of positive autobiographical reasoning and personal responsibility taken in repeated narratives of interpersonal transgressions as predictors of growth in empathy, humility, and compassion over time. In our pre-registered prospective longitudinal study design, we did not find meaningful, robust effects of narration on personality development in the face of interpersonal adversity in romantic relationships. We consider several explanations for our small or null effects, and discuss the implications for advancing research into adversarial growth.

First, we note that individuals' use of positive autobiographical reasoning was related to their character traits across the models. Indeed, greater positive autobiographical reasoning was cross-sectionally associated with compassion (at Wave 2) and humility (at Wave 2) and baseline levels of empathy. For compassion, we also observed an unexpected effect, such that positive autobiographical reasoning at Wave 3 predicted less compassion at Wave $4^{3}$. However, despite these associations, autobiographical reasoning did not predict change in character traits over time. In fact, there was no mean-level change over time when we examined the character traits without including the narrative predictor variables, and the slopes for the associations that were modeled when the narrative predictors were included were very small in all cases.

This raises some important theoretical questions on whether changes in character traits are the optimal operationalization and measurement of adversarial growth. The focus on character traits - specifically empathy and humility using the trait questionnaires in this study - was determined by the scope of the larger grant project in which this study was part. The Pathways to Character project specifically set out to systematically investigate character growth following adversity. However, more recently, Chopik et al. (2020) found character traits were highly stable over time in a large sample of army personnel whom were followed before and after their first deployment. Additionally, other longitudinal investigations while not utilizing a prospective design have similarly not found consistent evidence of character growth following adversity (Lamade et al., 2020; Schueller et al., 2015). Future prospective research is needed to examine whether there is sufficient change and variability in character traits over time after adversity in more diverse populations than in this current study and the military to determine the merit of this operationalization of adversarial growth. Both the current study and Chopik et al. (2020) have examined character growth in either unique populations where stability or resilience might be more likely (e.g., military) or unique adverse events (as in this study) where it might

\footnotetext{
3 Given the lack of evidence for other character strengths, that this finding was opposite of expectations, and the one-time effect (i.e., we did not see this at other waves), we do not put much weight on this finding.
} 
be more challenging for people to reflect and change in response to self-threatening events (e.g., relational transgressions).

This current paper also sought to investigate narration as a mechanism for adversarial growth. In terms of the implications of these null (and in some instances contrary-to-expectations findings), the first possibility is that narration is not a mechanism for the development of character strengths following adversity. Before feeling secure in this interpretation, however, it seems that further work is needed, particularly given prior research that has found support for such models (e.g., Adler et al., 2015; Lilgendahl \& McLean, 2020; Lodi-Smith et al., 2009; Pals, 2006). We suggest that there are three concerns that need further attention.

First, to expand on an earlier point, it is difficult to conclude about the role of narration when there was little change in the actual character traits in this 12month period. In order to predict mechanisms of personality development, it is helpful to have more robust development. Thus, either using more temporal outcome measures (e.g., state v. trait), or employing a longer timeframe would be fruitful. However, it is also possible that this kind of personality development and change is simply not common, or requires much more intentional goal formation (e.g., Hudson, et al., 2019).

Second, it is possible that the relational transgressions wrote about by people in this current study were not seismic and impactful enough to cause meaningful change in character traits, though our analyses of severity as a moderator do not support this possibility. We asked for the events to be meaningful over the course of the last three months, but given that we were using a prospective design the events were not specified as deeply impactful to one's identity, such as is the case with selfdefining memories or the lowest point in one's life story, which are the types of events that have been examined in prior studies that have examined narration and psychological growth (e.g., Bauer et al., 2005; Pals, 2006). In our design, asking participants to continue writing about and reflecting on recent events that were not particularly impactful in their romantic relationships may have dampened the possibility for seeing character growth. We note that much of the literature on personal growth in narratives has used narrative prompts that focus on life challenges conceptualized as low points or traumas that often happen to (not caused by) people (e.g., Pals, 2006), or event prompts that are designed to access perceived growth, such as turning points (e.g., Bauer et al., 2005).

Alternatively, it is possible that the problem was not with the types of events participants narrated, but due to the methodological weakness of the narrative prompt itself. It is possible that the narrative instructions were too subtle and nondirective to induce the psychological reflection required to change long-standing personality traits. While this is possible, we did model our narrative instructions on previous studies and similar inductions have predicted trait change (e.g., Adler, 2012; Lodi-Smith et al., 2009), therefore we suspect that this explanation is less likely to account for the null results entirely, and if it has an influence it operates alongside the aforementioned issues on the types of events narrated.

Finally, relational transgressions might be a particularly challenging type of event from which to grow because the threat to the self is strongly implicated in the event itself. The desire to repair or protect one's self may be much stronger that the 
desire to admit the fault in order to grow. Indeed, the nascent research on this topic is mixed with regards to the potential for individuals to learn from transgressions. On the one hand, researchers have found that people try to minimize the harm caused to their partner by their actions when narrating about transgressions they have committed against their romantic partner (Cameron et al., 2002; Feiring et al., 2020). The use of redemption in narratives has been found to predict higher levels of forgiveness of a partner's infidelity, but it predicts lower levels when narrating one's own infidelity (Wilkinson \& Dunlop 2020). Yet, on the other hand, researchers have found that narrative reflection on relational transgressions is associated with wisdom, self-compassion and forgiveness (Mansfield et al., 2015; Mansfield et al., 2010), and the degree of insight is greater in the perpetrators' viewpoint when a constructive narrative of a transgression is constructed, which in turn is associated with greater problem solving within the relationship (Feiring et al., 2020; Fiering et al., 2017). As outlined in our theoretical rationale, we selected the narrative themes examined in this study on conceptual similarity to adversarial growth, and from past longitudinal research that had established a relationship between similar narrative themes and positive functioning (e.g., Adler et al., 2015; Lilgendahl \& McLean, 2020). However, given the unique nature of the transgression narratives in this study, where participants had to reflect on their own recent failures, it is possible that the examination of other narrative themes might have yielded changes in character (but see Mansfield et al., 2015 for similar narrative themes in the context of transgressions). For example, a key component of empathy is to recognize the perspectives of others (Davis, 1980), therefore future research on this data could examine this construct alongside other themes - not specified in our pre-registration - to explore which narrative themes may predict character growth in this context ${ }^{4}$.

Despite these limitations, we purposefully chose relational transgressions for two reasons. First, we assumed everyone would have an event to report over the course of a relatively short-term prospective study, an assumption that would not be fair were we to conceptualize adversity as trauma more broadly. Second, and as highlighted above, there is research that reflection on transgressions is beneficial, and therefore we wanted to broaden the conceptual scope of the conditions under which adversarial growth is investigated. However, both the design and conceptual constraints needed to address questions of adversarial growth are substantial, including a prospective longitudinal design that encompasses enough time for meaningful personality development, as well as assurance that all participants will have experienced an adverse event to narrate.

The final issue that we raise is that we modeled narrative as a mechanism for adversarial growth for several reasons, including our theoretical basis (McLean et al., 2007), conceptual similarities to mechanisms proposed in theories of adversarial growth (Joseph \& Linley, 2005; Tedeschi \& Calhoun, 2004), and due to the notion that narrative is an activity, thus likely to be an engine of change. We will now return to this last point regarding the activity of repeated narration to discuss an alternate conceptualization of narration as a mechanism for adversarial growth. Individual differences in narration can be modeled as an independent variable, as well as a

${ }^{4}$ We thank an anonymous reviewer for raising this point. 
dependent variable. In a recent paper, Lilgendahl and McLean (2020) found that narrative served different purposes depending on the valence of the narration and the associated construct. More specifically, positive self-event connections were associated with an increase in life satisfaction over time, and depression and anxiety predicted negative self-event connections over time. Thus, the dynamic of narrative, and the potential for bi-directional influences, make it a construct amenable to many different models. This raises the interesting question of how best to conceptualize adversarial growth as positive personality change (Jayawickreme et al., 2020), especially as some researchers have argued that adversarial growth should manifest itself through revision in the life story level of personality (Tedeschi \& Calhoun, 2004; Pals \& McAdams, 2004). We also note that examining change in narrative itself, as a level of personality, may be a particularly fruitful avenue, given that narrative is viewed as the most malleable level of personality (McAdams \& Pals, 2006). For example, we might see change in the repeated narration of specific stories (see Adler, 2019 for an overview) that signals change in the level of narrative identity in ways that are associated with positive well-being. Indeed, Adler (2012) examined the act of repeated narration among individuals participating in a 12week course of psychotherapy and found that their narratives increased in agency over time, and this increase in agency predicted improvements in mental health over time (even when controlling for changes in trait neuroticism). Yet, we note that this intriguing question is one for future research studies, as the design of this study does not permit a thorough investigation of this conceptualization. Specifically, to address this question, participants would need to repeatedly narrate the same event or set of events that they deemed to be centrally important to their identity, whereas our participants narrated recent relational stressors that for most individuals differed across waves.

In conclusion, this examination has revealed the challenges of a prospective examination of personality development in relation to adversarial growth. In the case of interpersonal character traits, we do not have solid evidence that narrative acts as a mechanism for their development. Yet we also have limitations that need to be addressed before reaching more firm conclusions. We appreciate the benefit of pre-registering our hypotheses and analytic plan so that these findings can be a part of the conversation on narration, personality development, and adversarial growth as this field progresses.

\section{Data Accessibility Statement:}

The study materials, data and analysis scripts used for this article can be found here: https://osf.io/y2zds/?view_only=07d22ef4ab504fdebbd15e5ef0191d6f 


\section{References:}

Adler, J. M. (2012). Living into the story: Agency and coherence in a longitudinal study of narrative identity development and mental health over the course of psychotherapy. Journal of Personality and Social Psychology, 102(2), 367-389. http://dx.doi.org/10.1037/a0025289

Adler, J. M. (2019). Stability and change in narrative identity: Introduction to the special issue on repeated narration. Qualitative Psychology, 6(2), 134-145. http://dx.doi.org/10.1037/qup0000155

Adler, J. M., Lodi-Smith, J., Philippe, F. L., \& Houle, I. (2016). The Incremental Validity of Narrative Identity in Predicting Well-Being: A Review of the Field and Recommendations for the Future. Personality and Social Psychology Review, 20(2), 142-175. https://doi.org/10.1177/1088868315585068

Adler, J. M., Turner, A. F., Brookshier, K. M., Monahan, C., Walder-Biesanz, I., Harmeling, L. H., ... \& Oltmanns, T. F. (2015). Variation in narrative identity is associated with trajectories of mental health over several years. Journal of Personality and Social Psychology, 108(3), 476-496. https://doi.org/10.1037/a0038601

Bauer, J. J., McAdams, D. P., \& Sakaeda, A. R. (2005). Interpreting the good life: Growth memories in the lives of mature, happy people. Journal of Personality and Social Psychology, 88(1), 203-217. https://doi.org/10.1037/0022-3514.88.1.203

Blackie, L. E. R., Roepke, A. M., Hitchcott, N., \& Joseph, S. (2016). Can people experience posttraumatic growth after committing violent acts? Peace and Conflict: Journal of Peace Psychology, 22(4), 409-412. https://doi.org/10.1037/pac0000218

Blalock, D.V., Carton, J.M. \& Kashdan, T.B. (2014). Understanding post-traumatic growth by attending to contextual influences and developing wise interventions to measure it. European Journal of Personality, 28, 333-334. https://doi.org/10.1002/per.1970

Boals, A., \& Schuler, K. L. (2018). Reducing reports of illusory posttraumatic growth: A revised version of the Stress-Related Growth Scale (SRGS-R). Psychological Trauma: Theory, Research, Practice, and Policy, 10(2), 190-198. https://doi.org/10.1037/tra0000267

Boals, A., Bedford, L. A., \& Callahan, J. L. (2019). Perceptions of change after a trauma and perceived posttraumatic growth: A prospective examination. Behavioral Sciences, 9(1), 10. https://doi.org/10.3390/bs9010010

Brown, S. L., Chopra, P. K., \& Schiraldi, G. R. (2013). Validation of the Humility Inventory (HI), a five-factor, self-report measure of humility. The International Journal of Educational and Psychological Assessment, 12(2), 57-77.

Burnette, J. L., Davis, D. E., Green, J. D., Worthington, E. L., \& Bradfield, E. (2009). Insecure attachment and depressive symptoms: The mediating role of rumination, empathy, and forgiveness. Personality and Individual Differences, 46(3), 276-280. https://doi.org/10.1016/j.paid.2008.10.016

Cameron, J. J., Ross, M., \& Holmes, J. G. (2002). Loving the One You Hurt: Positive Effects of Recounting a Transgression against an Intimate Partner. Journal of Experimental Social Psychology, 38(3), 307-314. https://doi.org/10.1006/jesp.2001.1506

Cann, A., Calhoun, L. G., Tedeschi, R. G., Triplett, K. N., Vishnevsky, T., \& Lindstrom, C. M. (2011). Assessing posttraumatic cognitive processes: The Event Related Rumination 
Inventory. Anxiety, Stress, \& Coping, 24(2), 137-156.

https://doi.org/10.1080/10615806.2010.529901

Chopik, W. J., Kelley, W. L., Vie, L. L., Oh, J., Bonett, D. G., Lucas, R. E., \& Seligman, M. E. (2020, 26 May). Development of character strengths across the deployment cycle among US Army soldiers. Journal of Personality. Advanced Online Publication.

Davis, M. H. (1983). Measuring individual differences in empathy: Evidence for a multidimensional approach. Journal of Personality and Social Psychology, 44(1), 113126. https://doi.org/10.1037/0022-3514.44.1.113

Dunlop, W. L., \& Tracy, J. L. (2013). Sobering stories: Narratives of self-redemption predict behavioral change and improved health among recovering alcoholics. Journal of Personality and Social Psychology, 104(3), 576-590. https://doi.org/10.1037/a0031185

Feiring, C., Markus, J., \& Simon, V. A. (2020). Romantic conflict narratives in emerging adult couples: Viewpoint and gender matter. Family Process, 59(1), 127-141. https://doi.org/10.1111/famp.12418

Feiring, C., Milaniak, I., Simon, V. A., \& Clisura, L. (2017). Gender and negative emotion during narratives about romantic conflict: Links to conflict strategies. Journal of Relationships Research, 8, Article e7. https://doi.org/10.1017/jrr.2017.9

Fraley, R. C. (2019). Attachment in adulthood: Recent developments, emerging debates, and future directions. Annual Review of Psychology, 70, 401-422. https://doi.org/10.1146/annurev-psych-010418-102813

Frazier, P., Tennen, H., Gavian, M., Park, C., Tomich, P., \& Tashiro, T. (2009). Does selfreported posttraumatic growth reflect genuine positive change? Psychological Science, 20(7), 912-919. https://doi.org/10.1111/j.1467-9280.2009.02381.x

Habermas, T., \& Bluck, S. (2000). Getting a Life: The Emergence of the Life Story in Adolescence. Psychological Bulletin, 126(5), 748-769. https://doi.org/ 10.1037/0033-2909.126.5.748 https://doi.org/10.1111/jopy.12564

Hudson, N. W., Briley, D. A., Chopik, W. J., \& Derringer, J. (2019). You have to follow through: Attaining behavioral change goals predicts volitional personality change. Journal of Personality and Social Psychology, 117(4), 839857. https://doi.org/10.1037/pspp0000221

Jayawickreme, E., \& Blackie, L. E. R. (2014). Post-traumatic Growth as Positive Personality Change: Evidence, Controversies and Future Directions. European Journal of Personality, 28(4), 312-331. https://doi.org/10.1002/per.1963

Jayawickreme, E., Infurna, F., Alajak, K., Blackie, L.E.R., Chopik, W. J., Chung, J. M., Dorfmann, A., Fleeson, W., Foregard, M. J. C., Frazier, P., R. Michael, F., Grossmann, I., Heller, A. S., Laceuelle, O. M., Lucas, R. E., Luhmann, M., Luong, G., Meiher, L., McLean, K. C., Park, C. L..., Zonneveld, R. (2020, 26 August). Post-traumatic growth as positive personality change: Challenges, opportunities, and recommendations. Journal of Personality. Advanced Online Publication. https://doi/10.1111jopy.12591

Joseph, S., \& Linley, P. A. (2005). Positive Adjustment to Threatening Events: An Organismic Valuing Theory of Growth Through Adversity. Review of General Psychology, 9(3), 262-280. https://doi.org/10.1037/1089-2680.9.3.262

Joseph, S., Maltby, J., Wood, A. M., Stockton, H., Hunt, N., \& Regel, S. (2012). The Psychological Well-Being-Post-Traumatic Changes Questionnaire (PWB-PTCQ): 
Reliability and validity. Psychological Trauma: Theory, Research, Practice, and Policy, 4(4), 420-428. https://doi.org/10.1037/a0024740

Josselson, R. (2009). The present of the past: Dialogues with memory over time. Journal of Personality, 77, 647-668. http://dx.doi.org/10.1111/j .1467-6494.2009.00560.x

Kline, R. B. (2010). Promise and pitfalls of structural equation modeling in gifted research. In B. Thompson \& R. F. Subotnik (Eds.), Methodologies for conducting research on giftedness (p. 147-169). American Psychological Association. https://doi.org/10.1037/12079-007

Lamade, R. V., Jayawickreme, E., Blackie, L. E., \& McGrath, R. E. (2020). Are sequential sample designs useful for examining post-traumatic changes in character strengths? The Journal of Positive Psychology, 15(3), 292-299. https://doi.org/10.1080/17439760.2019.1610481

Lilgendahl, J. P., \& McLean, K. C. (2020). Narrative identity processes and patterns of adjustment across the transition to college: A developmentally contextualized approach. Journal of Personality and Social Psychology, 119(4), 960-977. https://doi.org/10.1037/pspp0000277

Linley, P. A., \& Joseph, S. (2004). Positive Change Following Trauma and Adversity: A Review. Journal of Traumatic Stress, 17(1), 11-21. https://doi.org/10.1023/B:JOTS.0000014671.27856.7e

Linley, P.A., \& Joseph, S. (2005). The human capacity for growth through adversity. American Psychologist, 60(3), 262-264. https://doi.org/10.1037/0003066X.60.3.262b

Lodi-Smith, J., Geise, A. C., Roberts, B. W., \& Robins, R. W. (2009). Narrating personality change. Journal of Personality and Social Psychology, 96(3), 679-689. https://doi.org/10.1037/a0014611

Luhmann, M., Fassbender, I., Alcock, M., \& Haehner, P. (2020). A dimensional taxonomy of perceived characteristics of major life events. Journal of Personality and Social Psychology. Advance online publication. https://doi.org/10.1037/pspp0000291

Mansfield, C. D., Mclean, K. C., \& Lilgendahl, J. P. (2010). Narrating traumas and transgressions: Links between narrative processing, wisdom, and well-being. Narrative Inquiry, 20(2), 246-273. https://doi.org/10.1075/ni.20.2.02man

Mansfield, C. D., Pasupathi, M., \& McLean, K. C. (2015). Is narrating growth in stories of personal transgressions associated with increased well-being, self-compassion, and forgiveness of others? Journal of Research in Personality, 58, 69-83. https://doi.org/10.1016/j.jrp.2015.05.008

McAdams, D. P. (2006). The Redemptive Self: Generativity and the Stories Americans Live By. Research in Human Development, 3(2-3), 81-100. https://doi.org/10.1080/15427609.2006.9683363

McAdams, D. P., \& Pals, J. L. (2006). A new Big Five: Fundamental principles for an integrative science of personality. American Psychologist, 61(3), 204-217. https://doi.org/10.1037/0003-066X.61.3.204

McAdams, D. P., Reynolds, J., Lewis, M., Patten, A.H., Bowman, P.J. (2001). When bad things turn good and good things turn bad: Sequences of redemption and contamination in life narrative and their relation to psychosocial adaptation in midlife adults and in students. Personality and Social Psychology Bulletin, 27, 474-485.

https://doi.org/10.1177/0146167201274008 
McCullough, M. E., Fincham, F. D., \& Tsang, J. A. (2003). Forgiveness, forbearance, and time: the temporal unfolding of transgression-related interpersonal motivations. Journal of Personality and Social Psychology, 84(3), 540-557. https://doi.org/10.1037/00223514.84.3.540

McLean, K. C., \& Lilgendahl, J. (2019). Narrative identity in adolescence and adulthood: Pathways of development. In D. P. McAdams, J. Tackett, \& R. Shiner (Eds.). The Handbook of Personality Development (pp. 418 - 432). Guilford.

McLean, K. C., Köber, C., \& Haraldsson, K. (2019). The repeated narration of specific events: What event repetition can tell us about the identity stability in mid-life (in press). Qualitative Psychology. 6(2), 146-155. https://doi.org/10.1037/qup0000154

McLean, K. C. \& Pasupathi, M. (2012). Looking forwards and looking backwards: Two approaches to identity development. Identity Special Issue: Reintegrating Erikson: A Theoretical and Empirical Synthesis of Eriksonian Identity Models,12, 8 - 28. https://doi.org/10.1080/15283488.2011.632363

McLean, K. C., Pasupathi, M., \& Pals, J. L. (2007). Selves Creating Stories Creating Selves: A Process Model of Self-Development. Personality and Social Psychology Review, 11(3), 262-278. https://doi.org/10.1177/1088868307301034

McLean, K. C., Syed, M., Pasupathi, M., Adler, J. M., Dunlop, W. L., Drustrup, D., ... \& McAdams, D. P. (2020). The empirical structure of narrative identity: The initial Big Three. Journal of Personality and Social Psychology, 119(4), 920-944. https://doi.org/10.1037/pspp0000247

Merrill, N., Waters, T. E. A., \& Fivush, R. (2016). Connecting the self to traumatic and positive events: Links to identity and well-being. Memory, 24(10), 1321-1328. https://doi.org/10.1080/09658211.2015.1104358

Owenz, M., \& Fowers, B. J. (2019). Perceived post-traumatic growth may not reflect actual positive change: A short-term prospective study of relationship dissolution. Journal of Social and Personal Relationships, 36(10), 3098-3116. https://doi.org/10.1177/0265407518811662

Paleari, F. G., Regalia, C., \& Fincham, F. (2005). Marital Quality, Forgiveness, Empathy, and Rumination: A Longitudinal Analysis. Personality and Social Psychology Bulletin, 31(3), 368-378. https://doi.org/10.1177/0146167204271597

Pals, J. L. (2006). Narrative Identity Processing of Difficult Life Experiences: Pathways of Personality Development and Positive Self-Transformation in Adulthood. Journal of Personality, 74(4), 1079-1110. https://doi.org/10.1111/j.1467-6494.2006.00403.x

Pals, J. L., \& McAdams, D. P. (2004). The transformed self: A narrative understanding of posttraumatic growth. Psychological Inquiry, 15(1), 65-69. https://www.jstor.org/stable/20447204

Park, C. L. (2010). Making sense of the meaning literature: an integrative review of meaning making and its effects on adjustment to stressful life events. Psychological Bulletin, 136(2), 257-301. https://doi.org/10.1037/a0018301

Park, C. L., Cohen, L. H., \& Murch, R. L. (1996). Assessment and prediction of stress-related growth. Journal of Personality, 64(1), 71-105. https://doi.org/10.1111/j.14676494.1996.tb00815.x

Pasupathi, M., \& Wainryb, C. (2010). Developing moral agency through narrative. Human Development, 53(2), 55-80. https://doi.org/10.1159/000288208 
Pasupathi, M., Mansour, E., \& Brubaker, J. R. (2007). Developing a Life Story: Constructing Relations between Self and Experience in Autobiographical Narratives. Human Development, 50(2-3), 85-110. https://doi.org/10.1159/000100939

Sandage, S., \& Worthington, E. (2010). Comparison of Two Group Interventions to Promote Forgiveness: Empathy as a Mediator of Change. Journal of Mental Health Counseling, 32(1), 35-57. https://doi.org/10.17744/mehc.32.1.274536n518571683

Schueller, S. M., Jayawickreme, E., Blackie, L. E., Forgeard, M. J., \& Roepke, A. M. (2015). Finding character strengths through loss: An extension of Peterson and Seligman (2003). The Journal of Positive Psychology, 10(1), 53-63.

https://doi.org/10.1080/17439760.2014.920405

Schumann, K., \& Dweck, C. S. (2014). Who accepts responsibility for their transgressions? Personality and Social Psychology Bulletin, 40(12), 1598-1610. https://doi.org/10.1177/0146167214552789

Schumann, K., \& Ross, M. (2010). Why women apologize more than men: Gender differences in thresholds for perceiving offensive behavior. Psychological Science, 21(11), 1649-1655. https://doi.org/10.1177/0956797610384150

Seery, M. D. \& Kondrak, C. L. (2014). Does trauma lead to special growth? European Journal of Personality, 28, 348-350. https://doi.org/10.1002/per.1970

Shiota, M. N., Keltner, D., \& John, O. P. (2006). Positive emotion dispositions differentially associated with Big Five personality and attachment style. The Journal of Positive Psychology, 1(2), 61-71. https://doi.org/10.1080/17439760500510833

Slade, M., Oades, L.G., \& Jarden, A. (2017). Why well-being and recovery? In Slade, M., Oades, L.G., \& Jarden, A. (Eds). Wellbeing, Recovery and Mental Health. (pp. 1-6). Cambridge University Press.

Slotter, E. B., \& Ward, D. E. (2015). Finding the silver lining: The relative roles of redemptive narratives and cognitive reappraisal in individuals' emotional distress after the end of a romantic relationship. Journal of Social and Personal Relationships, 32(6), 737-756. https://doi.org/10.1177/0265407514546978

Syed, M., \& Azmitia, M. (2010). Narrative and ethnic identity exploration: A longitudinal account of emerging adults' ethnicity-related experiences. Developmental Psychology, 46, 208-219. http://dx .doi.org/10.1037/a0017825 Thorne, A., Cutting, L., \& Skaw, D. (1998). Young adults' relationship memories and the life story: Examples or essential landmarks? Narrative Inquiry, 8, 237-268. http://dx.doi.org/10.1075/ni.8.2 .02tho

Syed, M., \& Nelson, S. C. (2015). Guidelines for establishing reliability when coding narrative data. Emerging Adulthood, 3, 375-387. http://dx.doi.org/10.1177/2167696815587648

Tedeschi, R. G., \& Calhoun, L. G. (1995). Trauma and transformation. Sage.

Tedeschi, R. G., \& Calhoun, L. G. (1996). The Posttraumatic Growth Inventory: Measuring the positive legacy of trauma. Journal of Traumatic Stress, 9(3), 455-472. https://doi.org/10.1002/jts.2490090305

Tedeschi, R. G., \& Calhoun, L. G. (2004). Posttraumatic Growth: Conceptual Foundations and Empirical Evidence. Psychological Inquiry, 15(1), 1-18. https://doi.org/10.1207/s15327965pli1501_01 
Tennen, H., \& Affleck, G. (2002). Benefit-finding and benefit-reminding. In C. R. Snyder \& S. J. Lopez (Eds.), Handbook of positive psychology. (pp. 584-597). Oxford University Press.

Weiner, B. (2007). On Responsibility Inferences and the Perceived Moral Person. International Journal of Existential Positive Psychology, 1(1), 1708-1696.

Wilkinson, D. E., \& Dunlop, W. L. (2020). Both sides of the story: Narratives of romantic infidelity. Personal Relationships. Advanced Online Publication. https://doi.org/10.1111/pere.12355

Worthington, Jun., Everett L. (1998). An empathy-humility-commitment model of forgiveness applied within family dyads. Journal of Family Therapy, 20(1), 59-76. https://doi.org/10.1111/1467-6427.00068

Yanez, B. R., Stanton, A. L., Hoyt, M. A., Tennen, H., \& Lechner, S. (2011). Understanding perceptions of benefit following adversity: How do distinct assessments of growth relate to coping and adjustment to stressful events? Journal of Social and Clinical Psychology, 30(7), 699-721. https://doi.org/10.1521/jscp.2011.30.7.699 
Table 2:

CFA Model Fit Statistics for full sample testing models A (1-factor), B (2-factors), and $C$ (3-factors).

\begin{tabular}{|c|c|c|c|c|c|c|c|c|c|c|}
\hline Model: & Wave: & $\begin{array}{l}\text { Chi- } \\
\text { square }\end{array}$ & df & $\begin{array}{l}\text { p- } \\
\text { value }\end{array}$ & CFI & SSBIC & RMSEA & $\begin{array}{l}\mathbf{9 0 \%} \\
\text { CI } \\
\text { RMSEA }\end{array}$ & SRMR & $\mathbf{n}$ \\
\hline A & 1 & 1044.686 & 324 & .000 & 0.638 & 22104.583 & 0.085 & $\begin{array}{l}0.079 \\
0.090\end{array}$ & 0.089 & 310 \\
\hline B & 1 & 1004.260 & 323 & .000 & 0.658 & 22056.220 & 0.082 & $\begin{array}{l}0.077 \\
0.088\end{array}$ & 0.089 & 310 \\
\hline $\mathrm{C}$ & 1 & 792.296 & 321 & .000 & 0.763 & 21822.621 & 0.069 & $\begin{array}{l}0.063 \\
0.075\end{array}$ & 0.078 & 310 \\
\hline A & 2 & 1223.622 & 324 & .000 & 0.620 & 21290.010 & 0.095 & $\begin{array}{l}0.089 \\
0.101\end{array}$ & 0.102 & 307 \\
\hline B & 2 & 1200.422 & 323 & .000 & 0.629 & 21253.711 & 0.094 & $\begin{array}{l}0.088 \\
0.100\end{array}$ & 0.104 & 307 \\
\hline $\mathrm{C}$ & 2 & 922.007 & 321 & .000 & 0.746 & 20938.900 & 0.078 & $\begin{array}{l}0.072 \\
0.082\end{array}$ & 0.088 & 307 \\
\hline A & 3 & 1163.990 & 324 & .000 & 0.594 & 18224.083 & 0.099 & $\begin{array}{l}0.092 \\
0.105\end{array}$ & 0.109 & 267 \\
\hline B & 3 & 1112.801 & 323 & .000 & 0.618 & 18154.057 & 0.096 & $\begin{array}{l}0.090 \\
0.102\end{array}$ & 0.107 & 267 \\
\hline $\mathrm{C}$ & 3 & 882.353 & 321 & .000 & 0.728 & 17890.227 & 0.081 & $\begin{array}{l}0.075 \\
0.087\end{array}$ & 0.094 & 267 \\
\hline A & 4 & 1022.365 & 324 & .000 & 0.663 & 15895.371 & 0.095 & $\begin{array}{l}0.089 \\
0.102\end{array}$ & 0.099 & 238 \\
\hline B & 4 & 1008.735 & 323 & .000 & 0.669 & 15874.845 & 0.094 & $\begin{array}{l}0.088 \\
0.101\end{array}$ & 0.100 & 238 \\
\hline $\mathrm{C}$ & 4 & 752.127 & 321 & .000 & 0.792 & 15577.071 & 0.075 & $\begin{array}{l}0.068 \\
0.082\end{array}$ & 0.084 & 238 \\
\hline A & 5 & 1036.648 & 324 & .000 & 0.624 & 15464.487 & 0.098 & $\begin{array}{l}0.091 \\
0.104\end{array}$ & 0.099 & 230 \\
\hline B & 5 & 931.480 & 323 & .000 & 0.679 & 15342.735 & 0.091 & $\begin{array}{l}0.084 \\
0.097\end{array}$ & 0.099 & 230 \\
\hline $\mathrm{C}$ & 5 & 734.345 & 321 & .000 & 0.782 & 15109.741 & 0.075 & $\begin{array}{l}0.068 \\
0.082\end{array}$ & 0.083 & 230 \\
\hline
\end{tabular}

Note. Model A has 1-factor called interpersonal virtues; Model B has 2-factors called empathy and humility; Model C has 3-factors called empathy, humility and compassion. 
Table 3:

Coefficients for linear growth curve model predicting empathy across waves 1 to 5 with positive autobiographical reasoning and targeted covariates ( $n=305)$.

\begin{tabular}{|c|c|c|c|c|}
\hline & $\begin{array}{l}\text { Unstandardized } \\
\text { Estimate }\end{array}$ & S.E & p-value & $\begin{array}{l}\text { Standardized } \\
\text { Estimate } \\
\text { (STDYX) }\end{array}$ \\
\hline \multicolumn{5}{|l|}{ Intercept: } \\
\hline Sample location & 0.156 & 0.055 & $0.004^{* *}$ & 0.180 \\
\hline Gender & -0.083 & 0.057 & 0.145 & -0.093 \\
\hline PAR & 0.115 & 0.041 & $0.005^{* *}$ & 0.191 \\
\hline \multicolumn{5}{|l|}{ Slope: } \\
\hline Sample location & 0.003 & 0.006 & 0.552 & 0.059 \\
\hline Gender & -0.001 & 0.005 & 0.780 & -0.025 \\
\hline PAR & 0.000 & 0.004 & 0.993 & 0.001 \\
\hline \multicolumn{5}{|l|}{ Empathy at W2: } \\
\hline PAR at W2 & -0.017 & 0.014 & 0.229 & -0.032 \\
\hline \multicolumn{5}{|l|}{ Empathy at W3: } \\
\hline PAR at W3 & 0.015 & 0.017 & 0.359 & -0.031 \\
\hline $\begin{array}{l}\text { Repeated } \\
\text { narration at W3 }\end{array}$ & 0.028 & 0.028 & 0.304 & 0.025 \\
\hline \multicolumn{5}{|l|}{ Empathy at W4: } \\
\hline PAR at W4 & -0.021 & 0.023 & 0.379 & -0.036 \\
\hline $\begin{array}{l}\text { Repeated } \\
\text { narration at W4 }\end{array}$ & -0.013 & 0.042 & 0.762 & -0.011 \\
\hline \multicolumn{5}{|l|}{ Empathy at W5: } \\
\hline PAR at W5 & -0.012 & 0.026 & 0.649 & -0.018 \\
\hline $\begin{array}{l}\text { Repeated } \\
\text { narration at W5 }\end{array}$ & -0.075 & 0.049 & 0.122 & -0.067 \\
\hline
\end{tabular}

Notes. $P A R=$ positive autobiographical reasoning; $\mathrm{W} \#$ = wave number; Repeated narration $=$ same transgression narrated $(\mathrm{Y} / \mathrm{N})$; sample location $=(\mathrm{UK} / \mathrm{US})$.

${ }^{*} p<.05,{ }^{* *} p<.01,{ }^{* * *} p<.001$ 
Table 4:

Coefficients for linear growth curve model predicting humility across waves 1 to 5 with positive autobiographical reasoning and targeted covariates $(n=305)$.

\begin{tabular}{lcccc}
\hline & $\begin{array}{c}\text { Unstandardized } \\
\text { Estimate }\end{array}$ & S.E & p-value & $\begin{array}{c}\text { Standardized } \\
\text { Estimate } \\
\text { (STDYX) }\end{array}$ \\
\hline $\begin{array}{l}\text { Intercept: } \\
\text { Sample location }\end{array}$ & 0.115 & 0.057 & $0.042^{*}$ & 0.137 \\
$\begin{array}{l}\text { Gender } \\
\text { PAR }\end{array}$ & -0.044 & 0.059 & 0.453 & -0.051 \\
Slope: & -0.037 & 0.037 & 0.322 & -0.063 \\
Sample location & 0.002 & 0.005 & 0.757 & 0.034 \\
Gender & -0.001 & 0.005 & 0.883 & -0.017 \\
$\begin{array}{l}\text { PAR } \\
\text { Humility at W2: }\end{array}$ & 0.004 & 0.004 & 0.234 & 0.141 \\
$\begin{array}{l}\text { PAR at W2 } \\
\text { Humility at W3: }\end{array}$ & 0.029 & 0.013 & $0.027 *$ & 0.057 \\
PAR at W3 & 0.001 & 0.015 & 0.929 & 0.003 \\
$\begin{array}{l}\text { Repeated } \\
\text { narration at W3 }\end{array}$ & -0.024 & 0.028 & 0.404 & -0.022 \\
Humility at W4: & & & & -0.060 \\
PAR at W4 & -0.033 & 0.022 & 0.130 & 0.013 \\
Repeated & & & & \\
narration at W4 & 0.014 & 0.040 & & -0.081 \\
Humility at W5: & & & 0.103 & -0.058 \\
PAR at W5 & -0.053 & 0.033 & 0.199 & \\
$\begin{array}{l}\text { Repeated } \\
\text { narration at W5 }\end{array}$ & -0.066 & 0.051 & & \\
\hline
\end{tabular}

Notes. $P A R=$ positive autobiographical reasoning; $\mathrm{W} \#$ = wave number; Repeated narration $=$ same transgression narrated $(\mathrm{Y} / \mathrm{N})$; sample location $=(\mathrm{UK} / \mathrm{US})$.

${ }^{*} p<.05,{ }^{* *} p<.01,{ }^{* * *} p<.001$ 


\section{Table 5:}

Coefficients for linear growth curve model predicting compassion with within-person associations of positive autobiographical reasoning and repeated narration across wave 1 to $5(n=311)$.

\begin{tabular}{lcccc}
\hline & $\begin{array}{c}\text { Unstandardized } \\
\text { Estimate }\end{array}$ & S.E & p-value & $\begin{array}{c}\text { Standardized } \\
\text { Estimate } \\
\text { (STDYX) }\end{array}$ \\
\hline $\begin{array}{l}\text { Compassion at W2: } \\
\text { PAR at W2 }\end{array}$ & 0.069 & 0.024 & $0.005^{* *}$ & 0.070 \\
$\begin{array}{l}\text { Compassion at W3: } \\
\text { PAR at W3 }\end{array}$ & 0.031 & 0.034 & 0.362 & 0.035 \\
$\begin{array}{l}\text { Repeated } \\
\text { narration at W3 }\end{array}$ & 0.028 & 0.051 & 0.578 & 0.014 \\
$\begin{array}{l}\text { Compassion at W4: } \\
\text { PAR at W4 }\end{array}$ & & & \\
$\begin{array}{l}\text { Repeated } \\
\text { narration at W4 }\end{array}$ & -0.020 & 0.046 & 0.657 & -0.020 \\
$\begin{array}{l}\text { Compassion at W5: } \\
\text { PAR at W5 }\end{array}$ & 0.124 & 0.093 & 0.183 & 0.061 \\
$\begin{array}{l}\text { Repeated } \\
\text { narration at W5 }\end{array}$ & 0.117 & & & \\
\hline
\end{tabular}

Notes. $P A R=$ positive autobiographical reasoning; $\mathrm{W} \#$ = wave number; Repeated narration $=$ same transgression narrated $(\mathrm{Y} / \mathrm{N})$.

${ }^{*} p<.05,{ }^{* *} p<.01,{ }^{* * *} p<.001$ 
Table 6:

Coefficients for lagged linear growth curve models with positive autobiographical reasoning predicting empathy, humility and compassion across waves 1 to 5.

\begin{tabular}{|c|c|c|c|c|}
\hline & $\begin{array}{l}\text { Unstandardized } \\
\text { Estimate }\end{array}$ & S.E & p-value & $\begin{array}{l}\text { Standardized } \\
\text { Estimate } \\
\text { (STDYX) }\end{array}$ \\
\hline \multicolumn{5}{|c|}{ Model 1: Empathy $(\mathrm{n}=309)$} \\
\hline \multicolumn{5}{|l|}{ Intercept: } \\
\hline Sample location & 0.147 & 0.055 & $0.007^{* *}$ & 0.169 \\
\hline PAR & 0.111 & 0.041 & $0.007^{* *}$ & 0.184 \\
\hline \multicolumn{5}{|l|}{ Slope: } \\
\hline Sample location & 0.003 & 0.005 & 0.531 & 0.060 \\
\hline PAR & -0.001 & 0.004 & 0.734 & -0.033 \\
\hline \multicolumn{5}{|l|}{ Empathy W3: } \\
\hline $\begin{array}{l}\text { Repeated } \\
\text { narration W3 }\end{array}$ & 0.030 & 0.028 & 0.281 & 0.027 \\
\hline PAR W2 & -0.003 & 0.019 & 0.868 & -0.006 \\
\hline \multicolumn{5}{|l|}{ Empathy W4: } \\
\hline $\begin{array}{l}\text { Repeated } \\
\text { narration W4 }\end{array}$ & -0.004 & 0.041 & 0.919 & -0.004 \\
\hline PAR W3 & -0.015 & 0.022 & 0.495 & -0.030 \\
\hline \multicolumn{5}{|l|}{ Empathy W5: } \\
\hline $\begin{array}{l}\text { Repeated } \\
\text { narration W5 }\end{array}$ & -0.075 & 0.048 & 0.116 & -0.067 \\
\hline PAR W4 & 0.012 & 0.028 & 0.673 & 0.021 \\
\hline \multicolumn{5}{|c|}{ Model 2: Humility $(n=309)$} \\
\hline \multicolumn{5}{|l|}{ Intercept: } \\
\hline Sample location & 0.104 & 0.056 & 0.064 & 0.124 \\
\hline PAR & -0.010 & 0.038 & 0.797 & -0.017 \\
\hline \multicolumn{5}{|l|}{ Slope: } \\
\hline Sample location & 0.001 & 0.005 & 0.825 & 0.024 \\
\hline PAR & 0.003 & 0.004 & 0.453 & 0.094 \\
\hline \multicolumn{5}{|l|}{ Humility W3: } \\
\hline $\begin{array}{l}\text { Repeated } \\
\text { narration W3 }\end{array}$ & -0.029 & 0.027 & 0.291 & -0.027 \\
\hline PAR W2 & -0.003 & 0.017 & 0.874 & -0.005 \\
\hline \multicolumn{5}{|l|}{ Humility W4: } \\
\hline $\begin{array}{l}\text { Repeated } \\
\text { narration W4 }\end{array}$ & 0.010 & 0.041 & 0.808 & 0.009 \\
\hline PAR W3 & -0.039 & 0.021 & 0.069 & -0.079 \\
\hline \multicolumn{5}{|l|}{ Humility W5: } \\
\hline $\begin{array}{l}\text { Repeated } \\
\text { narration W5 }\end{array}$ & -0.091 & 0.052 & 0.081 & -0.080 \\
\hline PAR W4 & -0.023 & 0.024 & 0.349 & -0.039 \\
\hline \multicolumn{5}{|c|}{ Model 3: Compassion $(n=311)$} \\
\hline Compassion W3: & & & & \\
\hline $\begin{array}{l}\text { Repeated } \\
\text { narration W3 }\end{array}$ & 0.005 & 0.048 & 0.921 & 0.002 \\
\hline PAR W2 & 0.006 & 0.025 & 0.816 & 0.006 \\
\hline Compassion W4: & & & & \\
\hline $\begin{array}{l}\text { Repeated } \\
\text { narration W4 }\end{array}$ & 0.116 & 0.085 & 0.175 & 0.057 \\
\hline PAR W3 & -0.082 & 0.035 & $0.019 *$ & -0.089 \\
\hline
\end{tabular}




\begin{tabular}{lllll}
\hline $\begin{array}{l}\text { Compassion W5: } \\
\text { Repeated }\end{array}$ & 0.052 & 0.115 & 0.649 & 0.025 \\
narration W5 & & & & \\
PAR W4 & 0.043 & 0.051 & 0.403 & 0.041 \\
\hline
\end{tabular}

Notes. $P A R=$ positive autobiographical reasoning; $\mathrm{W} \#$ = wave number; Repeated narration $=$ same transgression narrated $(\mathrm{Y} / \mathrm{N})$.

${ }^{*} p<.05,{ }^{* *} p<.01,{ }^{* * *} p<.001$ 
Table 7:

Coefficients for linear lagged growth curve models with empathy, humility and compassion predicting positive autobiographical reasoning across waves 2 to 5 .

\begin{tabular}{|c|c|c|c|c|}
\hline & $\begin{array}{l}\text { Unstandardized } \\
\text { Estimate }\end{array}$ & S.E & p-value & $\begin{array}{l}\text { Standardized } \\
\text { Estimate } \\
\text { (STDYX) }\end{array}$ \\
\hline \multicolumn{5}{|c|}{ Model 1: Empathy $(\mathrm{n}=311)$} \\
\hline \multicolumn{5}{|l|}{ Intercept: } \\
\hline Sample location & -0.274 & 0.147 & 0.061 & -0.147 \\
\hline Empathy & 0.386 & 0.181 & $0.033^{*}$ & 0.189 \\
\hline \multicolumn{5}{|l|}{ Slope: } \\
\hline Sample location & 0.006 & 0.019 & 0.739 & 0.031 \\
\hline Empathy & -0.029 & 0.028 & 0.301 & -0.130 \\
\hline \multicolumn{5}{|l|}{ PAR W3: } \\
\hline $\begin{array}{l}\text { Repeated } \\
\text { narration W3 }\end{array}$ & -0.076 & 0.127 & 0.552 & -0.034 \\
\hline Empathy W2 & 0.117 & 0.075 & 0.118 & 0.058 \\
\hline \multicolumn{5}{|l|}{ PAR W4: } \\
\hline $\begin{array}{l}\text { Repeated } \\
\text { narration W4 }\end{array}$ & 0.144 & 0.111 & 0.195 & 0.073 \\
\hline Empathy W3 & 0.047 & 0.122 & 0.698 & 0.027 \\
\hline \multicolumn{5}{|l|}{ PAR W5: } \\
\hline $\begin{array}{l}\text { Repeated } \\
\text { narration W5 }\end{array}$ & -0.072 & 0.141 & 0.611 & -0.041 \\
\hline Empathy W4 & 0.084 & 0.178 & 0.638 & 0.053 \\
\hline \multicolumn{5}{|c|}{ Model 2: Humility $(\mathrm{n}=311)$} \\
\hline \multicolumn{5}{|l|}{ Intercept: } \\
\hline Sample location & -0.233 & 0.153 & 0.127 & -0.125 \\
\hline Humility & 0.241 & 0.195 & 0.215 & 0.115 \\
\hline \multicolumn{5}{|l|}{ Slope: } \\
\hline Sample location & 0.005 & 0.019 & 0.796 & 0.024 \\
\hline Humility & -0.052 & 0.030 & 0.090 & -0.225 \\
\hline \multicolumn{5}{|l|}{ PAR W3: } \\
\hline $\begin{array}{l}\text { Repeated } \\
\text { narration W3 }\end{array}$ & -0.074 & 0.131 & 0.574 & -0.033 \\
\hline Humility W2 & 0.136 & 0.068 & $0.045^{*}$ & 0.067 \\
\hline \multicolumn{5}{|l|}{ PAR W4: } \\
\hline $\begin{array}{l}\text { Repeated } \\
\text { narration W4 }\end{array}$ & 0.127 & 0.111 & 0.254 & 0.064 \\
\hline Humility W3 & 0.132 & 0.123 & 0.281 & 0.071 \\
\hline \multicolumn{5}{|l|}{ PAR W5: } \\
\hline $\begin{array}{l}\text { Repeated } \\
\text { narration W5 }\end{array}$ & -0.089 & 0.143 & 0.535 & -0.049 \\
\hline Humility W4 & 0.205 & 0.177 & 0.247 & 0.122 \\
\hline \multicolumn{5}{|c|}{ Model 3: Compassion $(n=311)$} \\
\hline $\begin{array}{l}\text { PAR W3: } \\
\text { Repeated } \\
\text { narration W3 }\end{array}$ & 0.043 & 0.134 & 0.752 & 0.019 \\
\hline $\begin{array}{l}\text { Compassion W2 } \\
\text { PAR W4: }\end{array}$ & 0.035 & 0.037 & 0.347 & 0.034 \\
\hline $\begin{array}{l}\text { Repeated } \\
\text { narration W4 }\end{array}$ & 0.047 & 0.159 & 0.767 & 0.024 \\
\hline Compassion W3 & 0.018 & 0.069 & 0.798 & 0.018 \\
\hline
\end{tabular}




\begin{tabular}{|c|c|c|c|c|}
\hline $\begin{array}{l}\text { PAR W5: } \\
\text { Repeated } \\
\text { narration W5 }\end{array}$ & -0.274 & 0.255 & 0.282 & -0.156 \\
\hline Compassion W4 & 0.041 & 0.101 & 0.683 & 0.047 \\
\hline
\end{tabular}


Table 8:

Coefficients for linear growth curve model for interactions with event severity, narrative responsibility and positive autobiographical reasoning on empathy across waves 1-5.

\begin{tabular}{|c|c|c|c|c|}
\hline $\begin{array}{l}\text { Empathy } \\
(n=307)\end{array}$ & $\begin{array}{l}\text { Unstandardized } \\
\text { Estimate }\end{array}$ & S.E & p-value & $\begin{array}{c}\text { Standardized } \\
\text { Estimate } \\
\text { (STDYX) }\end{array}$ \\
\hline \multicolumn{5}{|l|}{ Intercept: } \\
\hline Sample location & 0.168 & 0.058 & $0.004^{* *}$ & 0.193 \\
\hline PAR & 0.134 & 0.032 & $0.000^{* * *}$ & 0.311 \\
\hline Event severity & 0.072 & 0.028 & $0.012^{*}$ & 0.167 \\
\hline Responsibility & -0.039 & 0.029 & 0.172 & -0.091 \\
\hline SeverityXPAR & 0.018 & 0.029 & 0.544 & 0.043 \\
\hline ResponsibilityXPAR & -0.095 & 0.033 & $0.004^{* *}$ & -0.207 \\
\hline ResponsbilityXSeverity & -0.034 & 0.031 & 0.269 & -0.075 \\
\hline SeverXRespoXPAR & -0.052 & 0.033 & 0.114 & -0.124 \\
\hline \multicolumn{5}{|l|}{ Slope: } \\
\hline Sample location & -0.002 & 0.006 & 0.661 & -0.043 \\
\hline PAR & -0.002 & 0.003 & 0.531 & -0.071 \\
\hline Event severity & -0.007 & 0.003 & $0.023^{*}$ & -0.244 \\
\hline Responsibility & -0.003 & 0.003 & 0.388 & -0.091 \\
\hline SeverityXPAR & 0.000 & 0.003 & 0.909 & -0.015 \\
\hline ResponsibilityXPAR & 0.009 & 0.003 & $0.002^{* *}$ & 0.315 \\
\hline ResponsbilityXSeverity & 0.004 & 0.004 & 0.313 & 0.123 \\
\hline SeverXRespoXPAR & 0.000 & 0.003 & 0.968 & -0.005 \\
\hline \multicolumn{5}{|l|}{ Empathy W2: } \\
\hline PAR W2 & -0.014 & 0.014 & 0.327 & -0.027 \\
\hline \multicolumn{5}{|l|}{ Empathy W3: } \\
\hline Repeated narration W3 & 0.042 & 0.028 & 0.134 & 0.038 \\
\hline PAR W3 & -0.017 & 0.017 & 0.319 & -0.034 \\
\hline \multicolumn{5}{|l|}{ Empathy W4: } \\
\hline Repeated narration W4 & 0.002 & 0.041 & 0.967 & 0.002 \\
\hline PAR W4 & -0.026 & 0.023 & 0.255 & -0.047 \\
\hline \multicolumn{5}{|l|}{ Empathy W5: } \\
\hline Repeated narration W5 & -0.055 & -1.155 & 0.248 & -0.049 \\
\hline PAR W5 & -0.016 & -0.605 & 0.545 & -0.024 \\
\hline
\end{tabular}

Notes. $P A R=$ positive autobiographical reasoning; $\mathrm{W} \#=$ wave number; Repeated narration $=$ same transgression narrated $(\mathrm{Y} / \mathrm{N})$; SeverityXPAR $=2$-way interaction between event severity and positive autobiographical reasoning; ResponsibilityXPAR = 2-way interaction between narrative responsibility and positive autobiographical reasoning; ResponsbilityXSeverity = 2-way interaction between narrative responsibility and event severity; everXRespoXPAR = 3-way interaction between event severity, narrative responsibility and positive autobiographical reasoning.

${ }^{*} p<.05,{ }^{* *} p<.01,{ }^{* * *} p<.001$ 
Table 9:

Coefficients for linear growth curve model for interactions with event severity, narrative responsibility and positive autobiographical reasoning on humility across waves 1-5.

\begin{tabular}{|c|c|c|c|c|}
\hline $\begin{array}{l}\text { Humility } \\
(n=307)\end{array}$ & $\begin{array}{l}\text { Unstandardized } \\
\text { Estimate }\end{array}$ & S.E & p-value & $\begin{array}{c}\text { Standardized } \\
\text { Estimate } \\
\text { (STDYX) }\end{array}$ \\
\hline \multicolumn{5}{|l|}{ Intercept: } \\
\hline Sample location & 0.115 & 0.060 & 0.054 & 0.136 \\
\hline PAR & 0.009 & 0.034 & 0.791 & 0.022 \\
\hline Event severity & 0.061 & 0.033 & 0.060 & 0.147 \\
\hline Responsibility & -0.018 & 0.033 & 0.580 & -0.043 \\
\hline SeverityXPAR & -0.001 & 0.032 & 0.972 & -0.003 \\
\hline ResponsibilityXPAR & -0.051 & 0.035 & 0.145 & -0.115 \\
\hline ResponsbilityXSeverity & -0.016 & 0.037 & 0.662 & -0.036 \\
\hline SeverXRespoXPAR & -0.012 & 0.035 & 0.740 & -0.028 \\
\hline \multicolumn{5}{|l|}{ Slope: } \\
\hline Sample location & -0.002 & 0.006 & 0.700 & -0.047 \\
\hline PAR & 0.002 & 0.003 & 0.521 & 0.096 \\
\hline Event severity & -0.001 & 0.004 & 0.720 & -0.059 \\
\hline Responsibility & -0.002 & 0.003 & 0.475 & -0.099 \\
\hline SeverityXPAR & 0.005 & 0.004 & 0.278 & 0.220 \\
\hline ResponsibilityXPAR & 0.006 & 0.003 & 0.107 & 0.231 \\
\hline ResponsbilityXSeverity & 0.000 & 0.004 & 0.911 & 0.020 \\
\hline SeverXRespoXPAR & -0.002 & 0.004 & 0.572 & -0.106 \\
\hline \multicolumn{5}{|l|}{ Humility W2: } \\
\hline PAR W2 & 0.032 & 0.013 & $0.016^{*}$ & 0.062 \\
\hline \multicolumn{5}{|l|}{ Humility W3: } \\
\hline Repeated narration W3 & -0.014 & 0.028 & 0.619 & -0.013 \\
\hline PAR W3 & 0.000 & 0.015 & 0.980 & 0.001 \\
\hline \multicolumn{5}{|l|}{ Humility W4: } \\
\hline Repeated narration W4 & 0.026 & 0.041 & 0.527 & 0.024 \\
\hline PAR W4 & -0.038 & 0.022 & 0.077 & -0.070 \\
\hline \multicolumn{5}{|l|}{ Humility W5: } \\
\hline Repeated narration W5 & -0.052 & 0.051 & 0.307 & -0.046 \\
\hline PAR W5 & -0.058 & 0.033 & 0.074 & -0.090 \\
\hline
\end{tabular}

Notes. $P A R=$ positive autobiographical reasoning; $\mathrm{W} \#=$ wave number; Repeated narration $=$ same transgression narrated $(\mathrm{Y} / \mathrm{N})$; SeverityXPAR $=2$-way interaction between event severity and positive autobiographical reasoning; ResponsibilityXPAR = 2-way interaction between narrative responsibility and positive autobiographical reasoning; ResponsbilityXSeverity = 2-way interaction between narrative responsibility and event severity; SeverXRespoXPAR = 3-way interaction between event severity, narrative responsibility and positive autobiographical reasoning.

${ }^{*} p<.05,{ }^{* *} p<.01,{ }^{* * *} p<.001$ 


\section{Figure 1:}

Interaction plot for 2-way interaction between positive autobiographical reasoning and narrative responsibility on empathy slope across waves 1 to 5

\section{Loop plot for ADJUSTED_PAR}

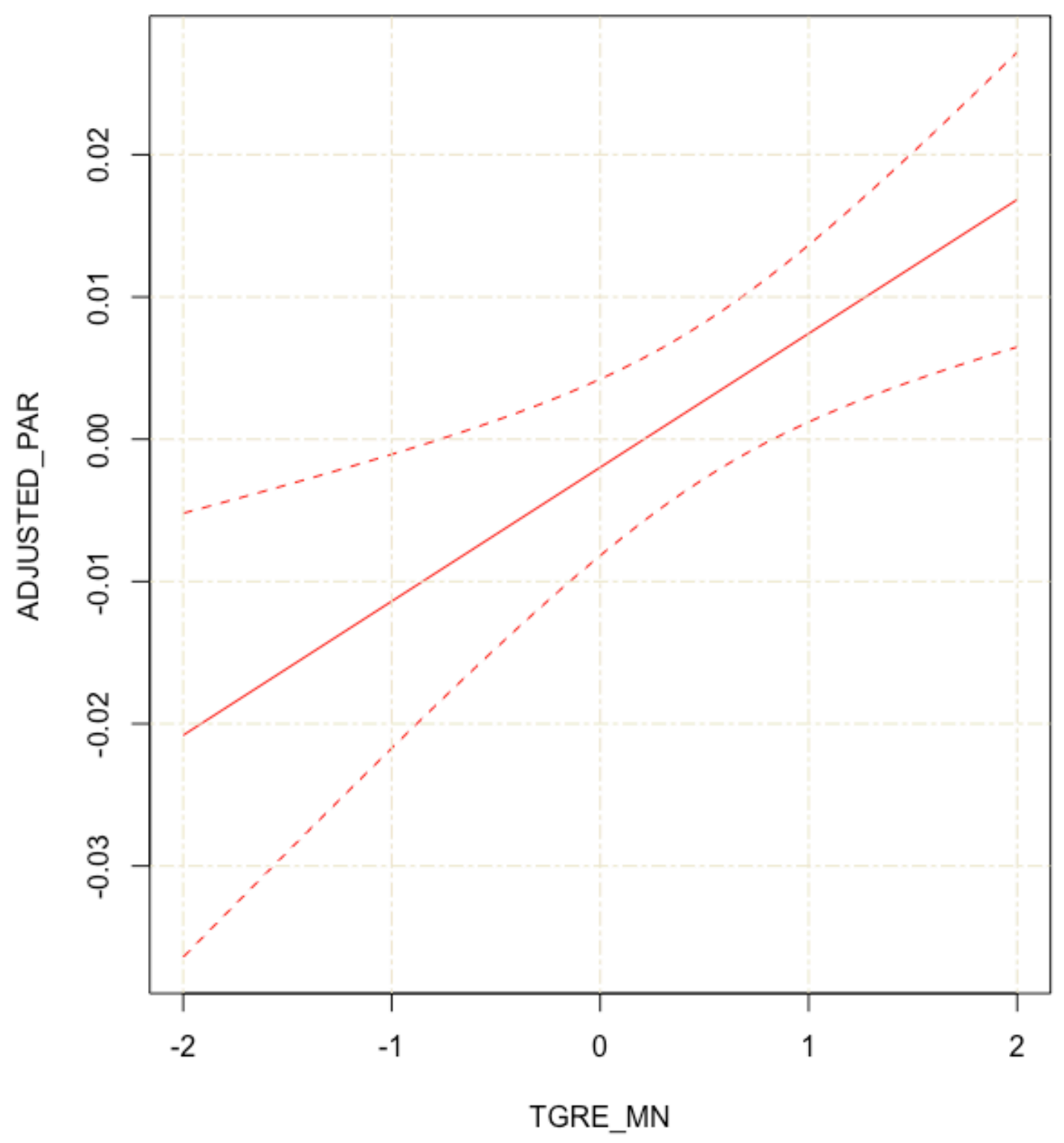

Note. TGRE_MN on X-axis is between-subjects narrative responsibility averaged across waves 2-5; Adjusted_PAR is the adjusted effect of positive autobiographical reasoning on empathy across waves $1-5$, which models the main effect of autobiographical reasoning by the magnitude of the interactive effect multiplied by main effect of narrative responsibility. 